1 Steel-Reinforced Grout (SRG) Strengthening of Shear-Critical RC Beams

2

3

4

5

6

7

8

9

10

11

12

13

14

15

16

17

18

19

20

21

22

23 1 2 3 4 5

- Nine shear critical RC beams where strengthened using SRG jacketing.

- The effectiveness of U- and fully-wrapped SRG jackets was investigated.

- Strength and deformation capacity increased up to $160 \%$ and $450 \%$, respectively.

- Digital Image Correlation confirmed the effectiveness of SRG jacketing.

- Expressions are proposed for estimating the effective strain of the SRG jacket.

6




\section{Steel-Reinforced Grout (SRG) Strengthening of Shear-Critical RC Beams}

\section{G.E Thermou ${ }^{\text {* }}$, V.K. Papanikolaou ${ }^{2}$, C. Lioupis $^{3}$ and I. Hajirasouliha ${ }^{4}$}

26

\footnotetext{
${ }^{1}$ Assistant Professor in Structural Engineering, Dept. of Civil Engineering, The University of Nottingham, NG7 2RD, Nottingham, UK

${ }^{2}$ Assistant Professor, Aristotle University of Thessaloniki, Dept. of Civil Engineering, 54124, Thessaloniki, Greece

${ }^{3}$ Civil Engineer, 41335, Larisa, Greece

${ }^{4}$ Senior Lecturer, Civil and Structural Engineering Department, The University of Sheffield, S1 3JD, Sheffield, UK
}

Abstract: This paper investigates the effectiveness of Steel-Reinforced Grout (SRG) jackets to strengthen shear critical reinforced concrete (RC) beams. Eleven RC beams were tested in three-point bending. Key parameters of investigation were the strengthening configuration (Uand fully-wrapped jackets), the density of the fabric $(1.57$ and 4.72 cords $/ \mathrm{cm})$ and the number of the strengthening layers (one and two). The test results demonstrated the efficiency of SRG jacketing in increasing both strength (up to 160\%) and deformation capacity (up to $450 \%$ ) of the shear critical beams. Expressions are proposed for estimating the effective strain of the SRG jacket.

Keywords: SRG; FRCM; Jackets; Steel fabric; Mortar; RC Beams; Shear; Strengthening

\footnotetext{
${ }^{*}$ Corresponding author, tel: +44 (0) 115 7487229, georgia.thermou@nottingham.ac.uk
} 


\section{Introduction}

The vast majority of reinforced concrete (RC) structures was built at times when general understanding about the importance of reinforcement detailing in seismic response was still at a premature stage. Poor material and construction quality as well as aging of materials (e.g. steel corrosion) are other key factors that increase the vulnerability of substandard structures to future earthquake events. In the pre-1970s construction practice, shear reinforcement generally comprised of smooth rectangular stirrups anchored with $90^{\circ}$ hooks in the ends, made of StI (yield strength $220 \mathrm{MPa}$ ) 6-8 mm diameter bars spaced at $250-300 \mathrm{~mm}$ on centres along the lengths of beams and columns [1]. Strength hierarchy checks performed on structural members with the aforementioned detailing, revealed that in most cases, and especially for beams, shear failure was the dominant mode of failure [1-3]. Such brittle failures can spread out across different locations of the building and jeopardize the overall structural integrity and ultimately lead to collapses.

In general, using externally bonded composites provides an effective way to alleviate deficiencies at local (member) level associated with shear critical members. Fibre Reinforced Polymer (FRP) jacketing is a popular and effective intervention method that has been used extensively for strengthening of substandard RC structures worldwide [e.g. 4-7]. However, FRP jacketing systems have several drawbacks, mainly related to the use of epoxy, such as poor behaviour to fire conditions, relatively high cost of epoxy resins and lack of vapour permeability with adverse effects on RC structures. In the last few years a new generation of mortar-based systems has been introduced, which retains the advantages of FRP applications but eliminates the previous shortcomings by using mortar instead of resin. Depending on the type of the textile, the following Fibre-Reinforced Cementitious Mortar (FRCM) systems have been developed: (i) TRM (Textile-Reinforced Mortar) where bidirectional textiles made of continuous carbon 
or glass fibres are applied using mortars [e.g. 8-10]; (ii) PBO-FRCM (poliparafenilen benzobisoxazole fibre-reinforced cementitious matrix) where PBO nets are embedded in a cement based matrix [e.g. 11-12]; and (iii) SRG (steel-reinforced grout) system where Ultra High Tensile Strength Steel (UHTSS) textiles are combined with inorganic binders [e.g. 13-23]. Several experimental studies have demonstrated the efficiency of TRM and PBO-FRCM jacketing at improving the response of shear critical beams (TRM [24-32], PBO-FRCM [3337]. Regardless of the adopted textile architecture, the number of layers and the jacket configuration, FRCM jackets have been proved quite efficient in increasing the shear capacity of deficient beams and in some cases activating flexural yielding. In case of SRG jacketing, the research conducted on shear strengthening of deficient RC beams is rather limited. In a recent study, Gonzalez-Libreros et al. [38] tested four beams retrofitted by adding U-shaped SRG jackets made of galvanized unidirectional sheets of an equivalent thickness of $0.27 \mathrm{~mm}$. Parameters of investigation were the shear reinforcement of the beams ( 2 beams with $\varnothing 6 / 200$ and 2 beams with $\varnothing 6 / 300$ ) and the textile installation (with and without anchors). The SRG jacketed beams failed in shear and similar cracking patterns were observed between the beams with and without anchors. In general, the addition of SRG jackets increased the shear strength of the beams. The presence of the anchors prevented detachment of the composite, but it did not increase the shear strength any further.

The main objective of this paper is to further investigate the role of key design parameters on the response of shear critical beams retrofitted with SRG jackets. An experimental study is carried out where one- or two-layered U-wrapped, U-wrapped with mechanical anchorage and fully-wrapped SRG jackets are applied to nine two-span beams (two additional beams are used as control specimens). The efficiency of two densities of Ultra-High Tensile Strength Steel (UHTSS) textiles is also examined (1.57 and $4.72 \mathrm{cords} / \mathrm{cm})$. The test results demonstrate the effectiveness of SRG jacketing in increasing both strength and deformation capacity of the 


\section{Experimental program}

\subsection{Specimen Details} steel (i.e. stirrups) would influence the response of the SRG jacketed beams, it was decided not

shear critical beams. It is shown that the fully-wrapped SRG jackets can substantially modify the response of the original member by allowing it to fail in flexure. The experimental values of the shear strength of the SRG strengthened beams are then compared to the predicted values using existing desigan guidelines. Based on the experimental data, new expressions are derived which relate the effective strain of the SRG jacket to its axial rigidity.

Eleven RC beams were tested in three-point bending with a clear span to depth ratio of $\alpha / d=$ 2.2. The beams are characterized as short and it is expected that a major portion of the load capacity after the inclined cracking will be due to load transfer by the compression strut. All beams had a rectangular cross section $200 \mathrm{~mm}$ in width and $300 \mathrm{~mm}$ in height and were 2000 mm long. The beams were divided into two groups (A and B) according to the arrangement of the longitudinal steel reinforcement. Group A comprised one control and four SRG strengthened beams, whereas Group B consisted of one control and five SRG strengthened beams.

The longitudinal tensile and compressive reinforcement in Group A beams comprised two bottom and two top 12-mm diameter bars $\left(\rho_{1}=0.75 \%\right)$, respectively (see Fig. 1). In case of Group B, the reinforcement of the beams consisted of longitudinal deformed steel bars with $2 \varnothing 10$ bars at the top and $4 \varnothing 16$ bars at the bottom of the cross-section of the beam $\left(\rho_{1}=1.60 \%\right)$. Deformed steel $8 \mathrm{~mm}$ diameter closed stirrups were distributed at a uniform spacing of $100 \mathrm{~mm}$ in the longer span $1100 \mathrm{~mm}$ in length. All the beams were designed to be deficient in shear in the shorter shear span (600 mm in length, Fig. 1). Although, the presence of transversal internal to be considered as an additional parameter of study, since the objective was to directly assess 
115 the efficiency of SRG jacketed on the retrofitted beams. Hence, no transverse reinforcement

116 was provided in the critical shorter shear span of $600 \mathrm{~mm}$ (Fig. 1), and the SRG jacketing was

117 only applied in the critical shear span. The anchorage zones for the longitudinal reinforcement

118 were $150-\mathrm{mm}$ in length and two stirrups of 8 -mm diameter were provided (Fig. 1).

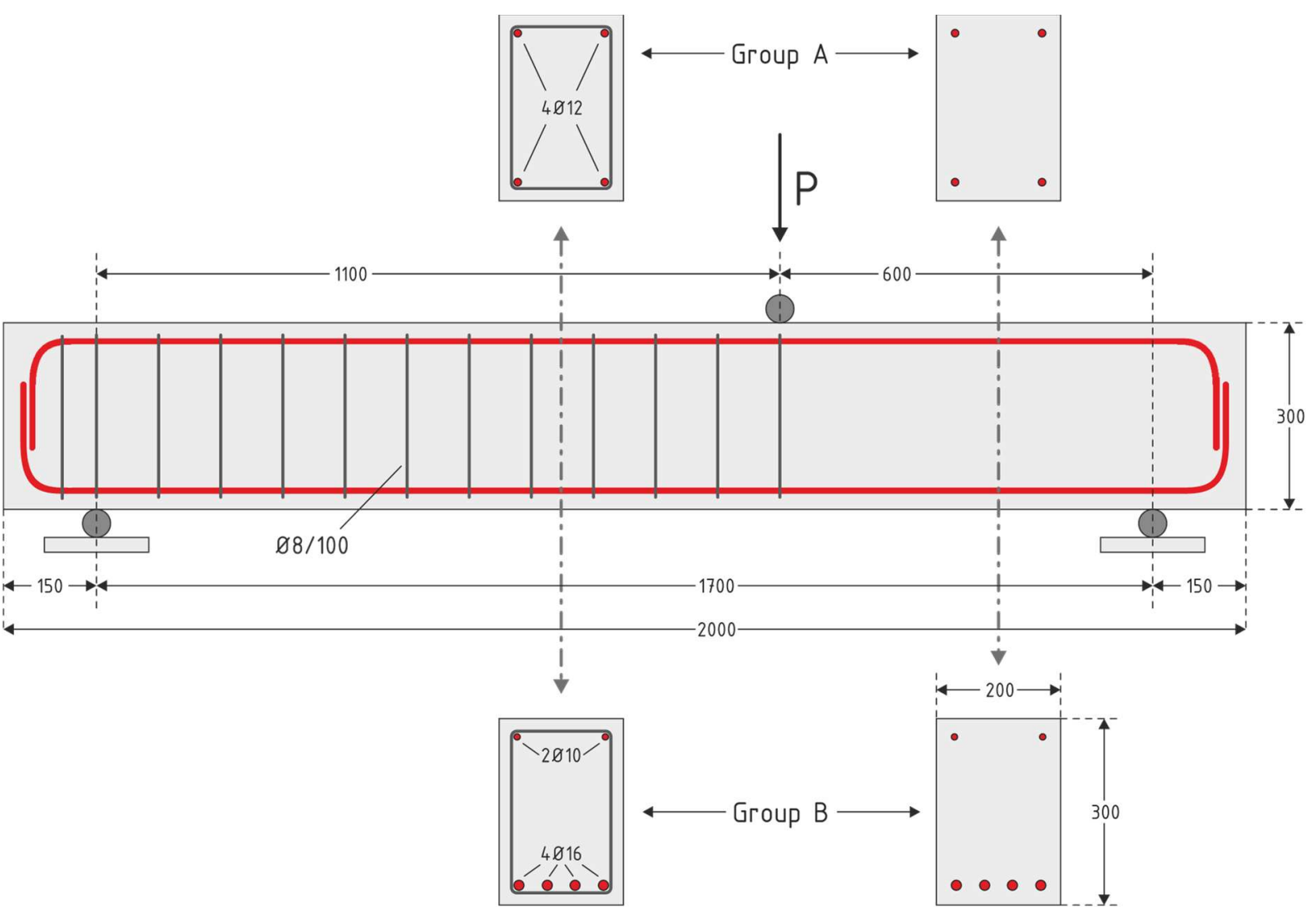

120 Figure 1: Geometry and reinforcement details of Group A and Group B beam specimens.

The key parameters of investigation were: (i) the density of the Ultra-High Tensile Strength

123 Steel(UHTSS) textile which was 1.57 and 4.72 cords/cm, (ii) the number of applied SRG layers

124 (one and two) and (iii) the strengthening configuration which consisted of U-wrapped, U-

125 wrapped with mechanical anchorage and fully-wrapped SRG jackets. The beams were given

126 the notation XYZW, where X stands for the group of the beams (A or B in Table 1), Y corresponds to the type of the jacketing system with 0 for the control specimen, $\mathrm{U}$ for the Uwrapped jacket, UM for the U-wrapped jackets with mechanical anchorage and F for the fully- 
wrapped jackets, $\mathrm{Z}$ indicates the density of the fabric with $\mathrm{L}$ and $\mathrm{H}$ for the 1.57 and 4.72

130 cords/cm fabrics, respectively, and finally $\mathrm{W}$ refers to the number of layers with 1 and 2 for

131 single- and double-layered SRG jackets. The details of all test specimens are given in Table 1. Table 1: Details of the specimens

\begin{tabular}{|c|c|c|c|c|c|}
\hline Group & Name & $\mathbf{f}_{\mathrm{c}}(\mathrm{MPa})$ & Type of jacket & $\begin{array}{c}\text { Density } \\
(\text { cords/cm) }\end{array}$ & Layers \\
\hline \multirow{5}{*}{ 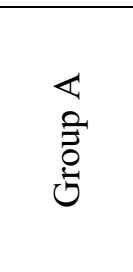 } & A0 & \multirow{5}{*}{28.0} & control & - & - \\
\hline & AUH1 & & U-wrapped & 4.72 & 1 \\
\hline & AUML1 & & $\begin{array}{c}\text { U-wrapped mechanical } \\
\text { anchorage }\end{array}$ & 1.57 & 1 \\
\hline & AFL1 & & Fully-wrapped & 1.57 & 1 \\
\hline & AFH1 & & Fully-wrapped & 4.72 & 1 \\
\hline \multirow{6}{*}{ 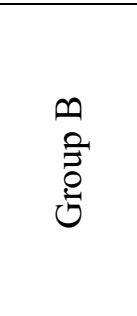 } & B0 & \multirow{6}{*}{23.3} & control & - & - \\
\hline & BUL1 & & U-wrapped & 1.57 & 1 \\
\hline & BUL2 & & U-wrapped & 1.57 & 2 \\
\hline & BUML1 & & $\begin{array}{c}\text { U-wrapped mechanical } \\
\text { anchorage }\end{array}$ & 1.57 & 1 \\
\hline & BFL1 & & Fully-wrapped & 1.57 & 1 \\
\hline & BFL2 & & Fully-wrapped & 1.57 & 2 \\
\hline
\end{tabular}

\subsection{Material Properties}

134 The RC beams of Group A were casted in one batch having an average compressive strength

135 of $\mathrm{f}_{\mathrm{c}}=28 \mathrm{MPa}$ (standard deviation, $\mathrm{SD}=2.47 \mathrm{MPa}$ ) at the day of the test obtained from six

136 standard cylinders $(150 \times 300 \mathrm{~mm})$. The beam specimens of Group B were casted in two batches

137 of three using the same mix. The average compressive strength at the day of the tests was $f_{c}=$

$13823.3 \mathrm{MPa}$ (standard deviation, $\mathrm{SD}=1.36 \mathrm{MPa}$ ), which was determined from the average of six

139 standard cylinders $(150 \times 300 \mathrm{~mm})$. The steel grade used for internal longitudinal (i.e. $\varnothing 10, \varnothing 12$,

$140 \varnothing 16)$ and transverse reinforcement (i.e. $\varnothing 8$ ) was B500C.

141 In this study, nine beams (four from Group A and five from Group B, see Table 1) were

142 retrofitted by using the SRG jacketing, in which externally bonded Ultra High Tensile Strength

143 Steel(UHTSS) textiles were embedded in an inorganic mortar matrix [13-14]. The textiles were

144 made of galvanized unidirectional high strength steel $3 \mathrm{X} 2$ cords fixed to a fiberglass micromesh 
145 to facilitate installation (see Fig. 2). The fiberglass micromesh keeps the cords in place without

146 contributing to strength of the composite system [39, 40]. Each cord was made by twisting five

147 individual wires; three straight filaments wrapped by two filaments at a high twist angle as

148 shown in Fig. 2. The geometrical and mechanical properties of the single cords are given in

149 Table 2 as provided by the manufacturers. More details regarding the stress-strain curve of the

150 cords can be found in Napoli et al. [39] and Santis et al. [40].

Table 2: Geometrical and mechanical properties of single cords as provided by the manufacturer

\begin{tabular}{ccccccc}
\hline Cord type & $\begin{array}{c}\text { Cord } \\
\text { diameter } \\
(\mathbf{m m})\end{array}$ & $\begin{array}{c}\text { Cord } \\
\text { area } \\
\left(\mathbf{m m}^{2}\right)\end{array}$ & $\begin{array}{c}\text { Break } \\
\text { load }(\mathbf{N})\end{array}$ & $\begin{array}{c}\text { Tensile } \\
\text { strength } \\
\boldsymbol{f}_{f u}(\mathbf{M P a})\end{array}$ & $\begin{array}{c}\text { Strain to failure } \\
\boldsymbol{\varepsilon}_{f u}(\mathbf{m m} / \mathbf{m m})\end{array}$ & $\begin{array}{c}\text { Elastic } \\
\text { modulus } \boldsymbol{E}_{\boldsymbol{f}} \\
(\mathbf{M P a})\end{array}$ \\
\hline $3 \times 2$ & 0.827 & 0.538 & 1506 & 2800 & 0.015 & 190000 \\
\hline
\end{tabular}

153

154

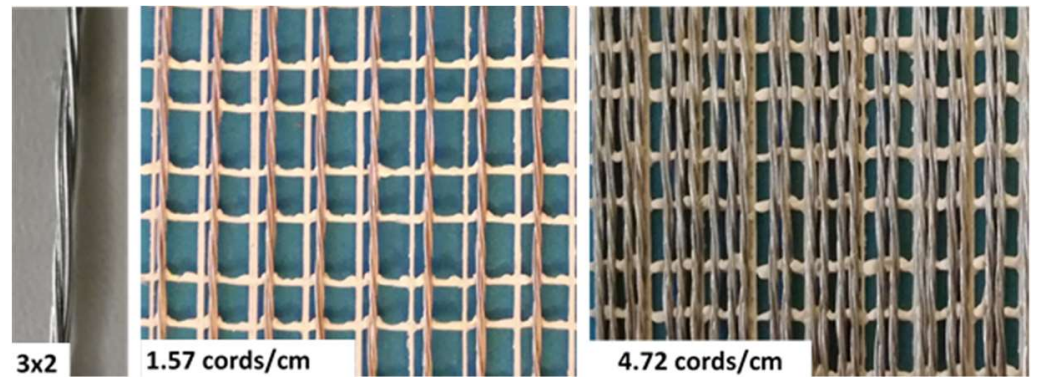

Figure 2: Steel cords and densities of the UHTSS textiles used

One of the critical design parameters of the SRG jacketing technique is the density of the textiles (i.e. the spacing between successive cords) since it should be designed to provide uninhibited flow of the cementitious grout through the steel fabric and develop adequate bond between the textile and the matrix [13]. Two different densities 1.57 and 4.72 cords/cm were examined in this experimental study with an equivalent thickness per unit width for a single layer of steel fabric, $\mathrm{t}_{\mathrm{f}}$, equal to 0.084 and $0.254 \mathrm{~mm}$, respectively (Table 1, Fig. 2). The axial stiffness of the textile, $K_{f}\left(=A_{f} \cdot E_{f}\right)$, which is directly related to the density of the textile, was calculated equal to 15960 and $48260 \mathrm{~N} / \mathrm{mm}$ for the 1.57 and the 4.72 cords/cm textiles, respectively (these figures should be doubled for the two-layered jackets). 
A commercial geo-mortar with a crystalline reaction geobinder base and a very low

166 petrochemical polymer content and free from organic fibres was used in this study. The component mortar was utilised as the substrate material applied to the concrete surface of the specimens, the bonding material between the applied layers of the steel fabric and as a final cover. The mechanical properties of the mortar appear in Table 3.

Table 3: Mechanical properties of the mortar at 28 days as provided by the manufacturer

171

\begin{tabular}{ccccc}
\hline Mortar & $\begin{array}{c}\text { Modulus of } \\
\text { elasticity } \\
\mathbf{E}_{\mathbf{m}} \text { (MPa) }\end{array}$ & $\begin{array}{c}\text { Flexural strength } \\
\mathbf{f}_{\mathbf{m f}}(\mathbf{M P a})\end{array}$ & $\begin{array}{c}\text { Compressive } \\
\text { strength } \\
\mathbf{f}_{\mathbf{m c}}(\mathbf{M P a})\end{array}$ & $\begin{array}{c}\text { Adhesive bond } \\
\mathbf{f}_{\mathbf{m b}} \text { (MPa) }\end{array}$ \\
\cline { 2 - 5 } & 25000 & 10.0 & 55.0 & 2.0 \\
\hline
\end{tabular}

\subsection{SRG Strengthening}

172 As mentioned above, nine RC beams (four from Group A and five from Group B) were

173 strengthened in the $600 \mathrm{~mm}$ shear critical span by applying the following three strengthening configurations: U-wrapped, U-wrapped with mechanical anchorage and fully-wrapped SRG jackets (see Table 1). The textiles originally were in roles of $300 \mathrm{~mm}$ width, thus 2 and 4 pieces of fabric were utilized for the single- and double-layered SRG jackets, respectively. Before starting the strengthening procedure, the fabrics were cut and pre-bent in order to follow the

178 shape of the jacket (Fig. 3). The edges of the beam cross section were not rounded, hence at these areas the fabrics were pre-bent at right angle. The sides of the beams were roughened using mechanical grinding to expose the aggregates and then were cleaned and saturated with water before proceeding to the application of the mortar (Fig. 4a). Subsequently, the mortar was

182 applied in approximately $3 \mathrm{~mm}$-thick layers manually with the help of a trowel directly onto 183 the lateral surface of the specimens (Fig. 4b). The textile was placed immediately after the 184 application of the cementitious mortar (Fig. 4c) and the mortar was squeezed out between the steel fibres by applying pressure manually. In case of the fully-wrapped one- and two-layered SRG jackets, after the application of the fabric to one and two full-cycles, respectively, the

187 remaining length, which was equal to the width of the beam $(200 \mathrm{~mm})$, was lapped over the top 
surface of the beam. It should be noted that in the case of two-layered fully-wrapped jackets the fabric was continuous, while in the case of two-layered U-wrapped jacket each layer was independent. Straight after the application of the first layer of the textile, the next layer of the mortar covered it completely and the second layer of the fabric was applied by following the procedure described above. A final coat of the cementitious mortar was applied to the exposed surface. The effect of SRG jacketing on the geometric dimensions of the specimens was small. Each layer of the mortar including the textile was 7 and $10 \mathrm{~mm}$ thick for the one- and twolayered SRG jackets, respectively.

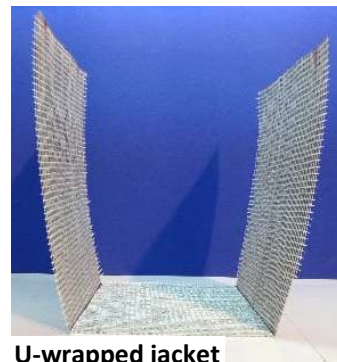

U-wrapped jacket

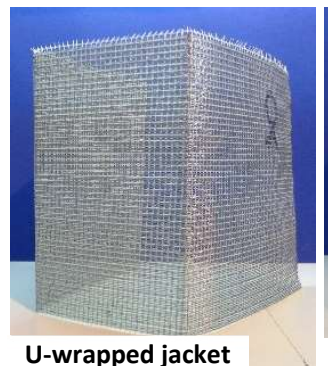

U-wrapped jacket

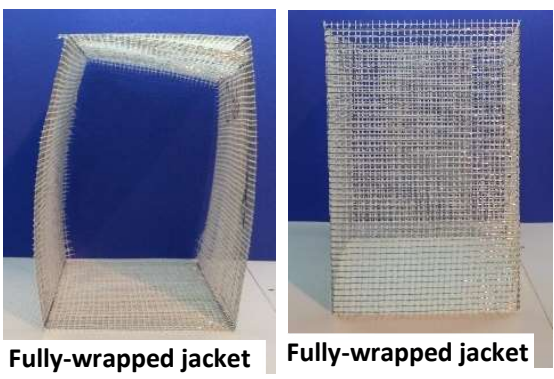

Fully-wrapped jacket

Figure 3: Preparation of the UHTSS textiles

In two of the beams (AUML1 and BUML1, see Table 1) a custom-made mechanical anchorage system was applied to enhance the anchorage of the U-wrapped SRG jackets to the concrete substrate. The system comprised four $700 \times 50 \times 5 \mathrm{~mm}$ metal plates $(2$ placed on each side of the beam), which covered the full-length of the strengthened area. The metal plates were drilled at their mid-height so that in total 9 holes were opened with $70 \mathrm{~mm}$ spacing (Fig. 5). The beams were drilled following the same pattern and the metal plates attached $50 \mathrm{~mm}$ above the upper fibre. Subsequently, the stud anchors were installed and properly wedged in the beam holes. A thin layer of mortar was applied onto the roughened concrete substrate and the fabric was then passed through the anchors and well stretched before the first metal plate was put in place. The free end-zone of the fabric, which was pre-bent, was wrapped over the first metal plate and then the second metal plate was put in place. The last stage involved screwing in the metal plates on each side of the beam to ensure that any sliding of the fabric would be avoided. 

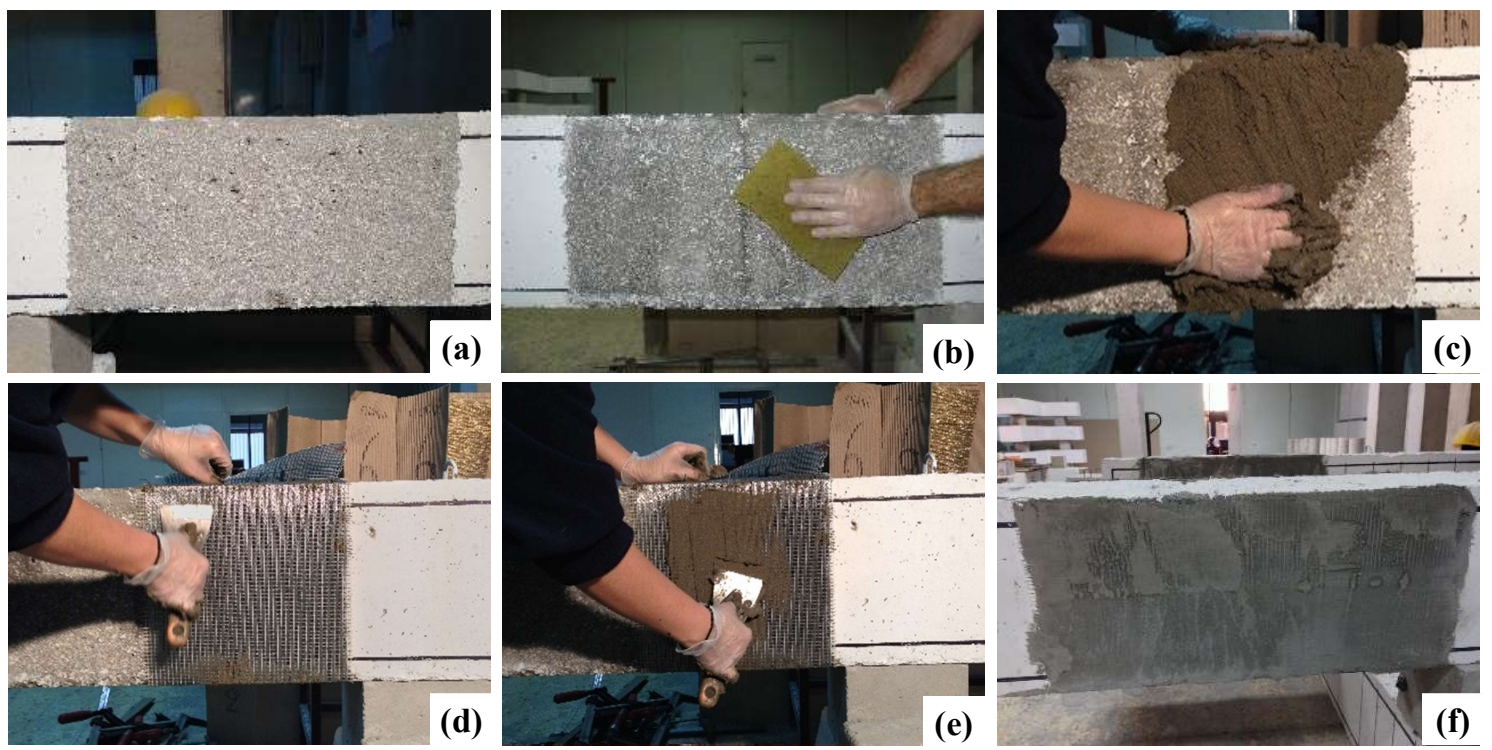

Figure 4: SRG jacketing application steps
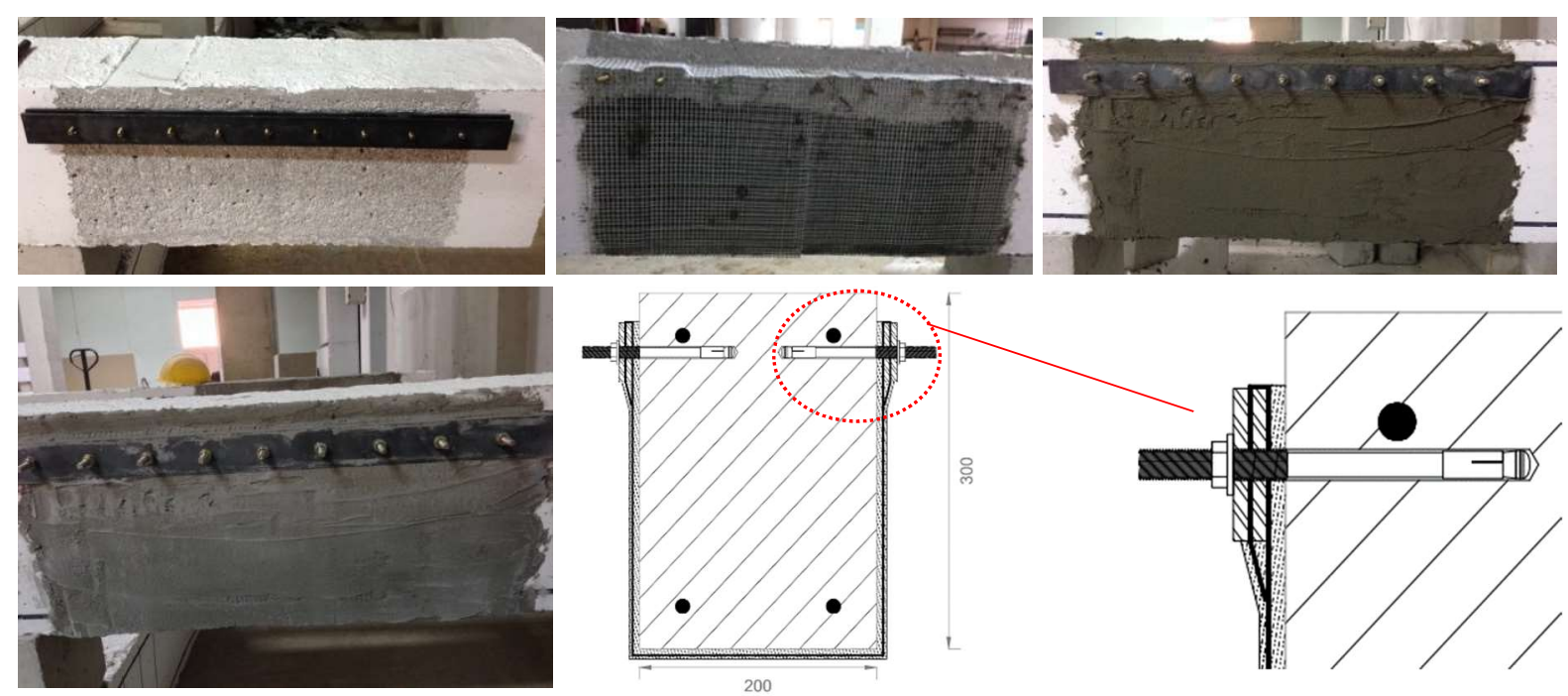

Figure 5: Preparation of the mechanical anchorage of the SRG U-wrapped beams

\subsection{Test setup and experimental methodology}

213 The employed three-point bending setup is depicted in Fig. 6. The RC beam was simply

214 supported on a pair of steel pedestals seated on the strong floor and anchored together with a

215 pair of threaded rods in order to prevent transverse sliding (span elongation) due to the second

216 order horizontal reactions at the beam supports. Loading was vertically applied by a $1000 \mathrm{kN}$

217 capacity single-ended actuator (MTS 243.60) using a displacement control system externally measured by a draw-wire sensor placed underneath the beam along the vertical loading axis. 
The external load was monotonically increased up to beam failure, which was triggered upon a

$22040 \%$ drop of the maximum measured reaction of the actuator load cell. The load was applied

221 at displacement rate $0.05 \mathrm{~mm} / \mathrm{sec}$. Moreover, a Digital Image Correlation (DIC) configuration

222 was utilised for capturing the strain contours of the tested beams [41]. The shear critical region

223 of each beam (the area of interest (AOI)) was painted with a speckle pattern using a special

224 brush and black ink. A DSLR camera was placed on a tripod at a distance, focusing on the

225 beam's AOI, remotely and automatically shuttered from the main acquisition controller at given

226 displacement intervals (4 photos per mm). Finally, the captured high-resolution speckle images

227 for each specimen were post-processed using a DIC software to produce strain contours at

228 characteristic points on the resulting load-displacement response curve.
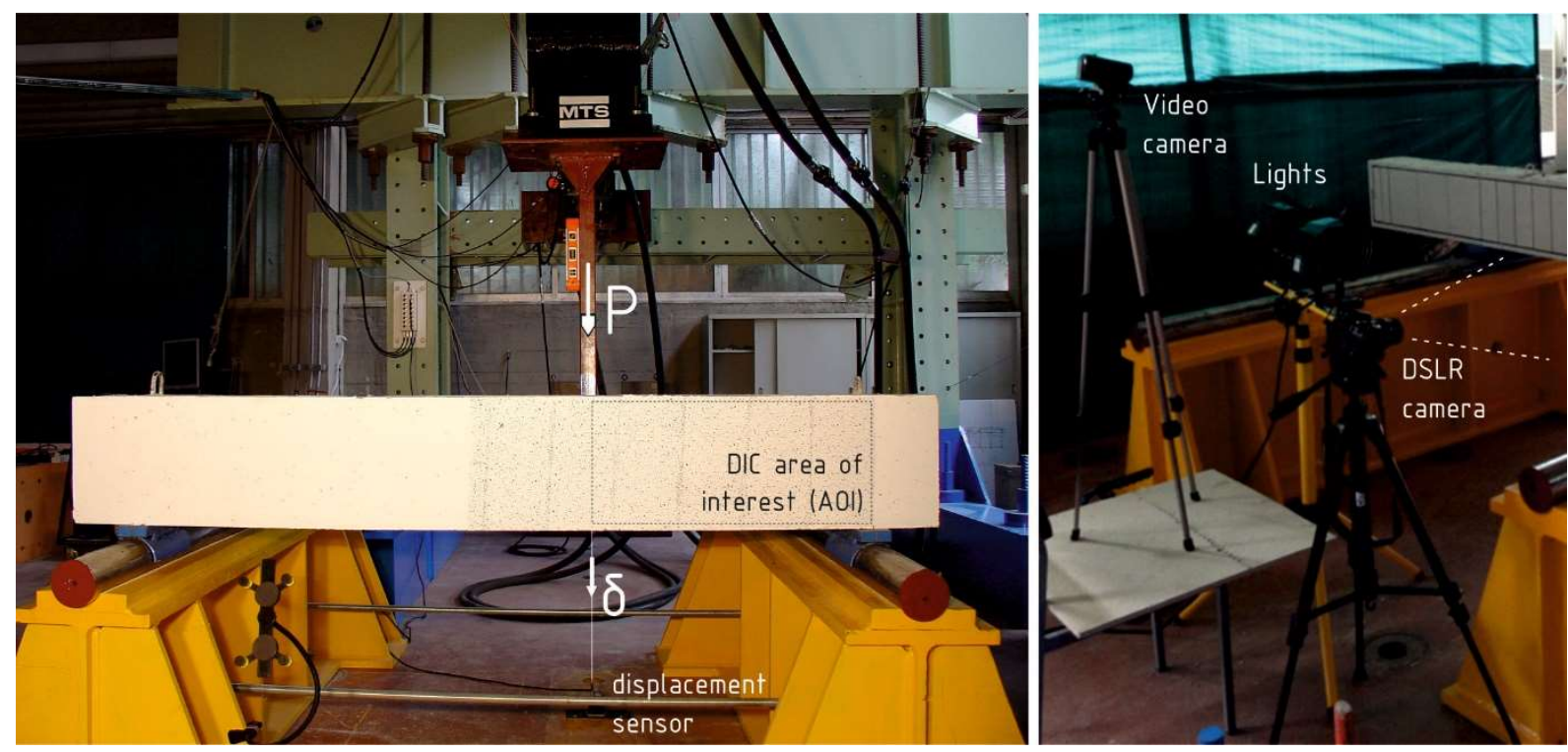

Figure 6: Test setup and details of instrumentation

\section{Test results and discussion}

\subsection{Failure modes}

231 The control beams of both Groups A and B (i.e. A0 and B0) exhibited a diagonal tension failure

232 mode as observed in Fig. 7. A single inclined crack along the loading and the support points

233 appeared in the shear span at the early stages of loading, which progressed further as the loading

234 increased leading to a brittle shear failure. 

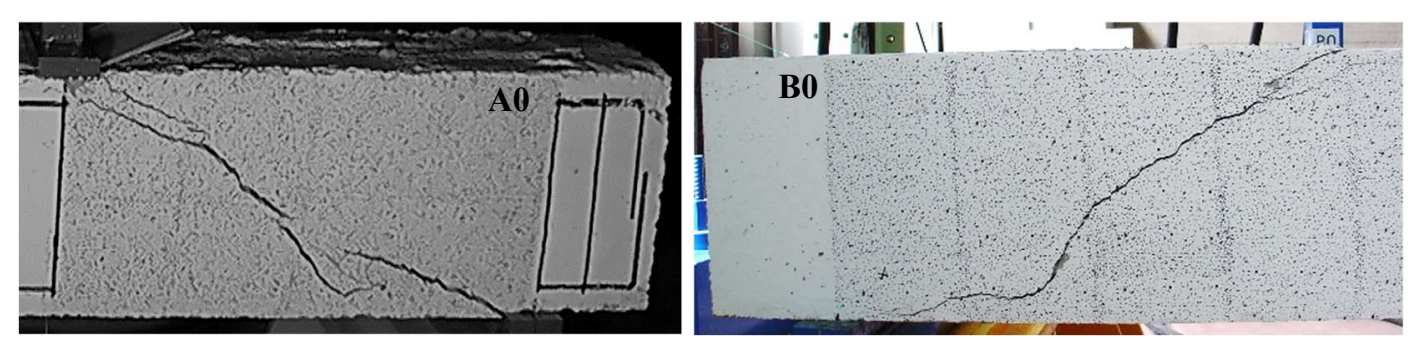

Figure 7: Failure mode of the control specimens

The different SRG jacketing schemes applied to the shear-critical beams of Group A led to

238 flexural failure of the strengthened beams (Fig. 8). The internal bottom steel reinforcement

239 reached yielding (i.e. $\varepsilon_{\mathrm{sy}}=\mathrm{f}_{\mathrm{sy}} / \mathrm{E}_{\mathrm{s}}=500 / 200000=0.0025$ for steel grade $\mathrm{B} 500 \mathrm{C}$. Strain

240 measurements were taken from the Digital Image Correlation (DIC) technique) and the beams

241 failed in a ductile manner, while flexural cracks formed on both sides of the applied point load

242 (Fig. 8). Apart from the cracks developed along the beam transverse direction that coincided

243 with the gap between successive cords, the textile did not show any further damage.
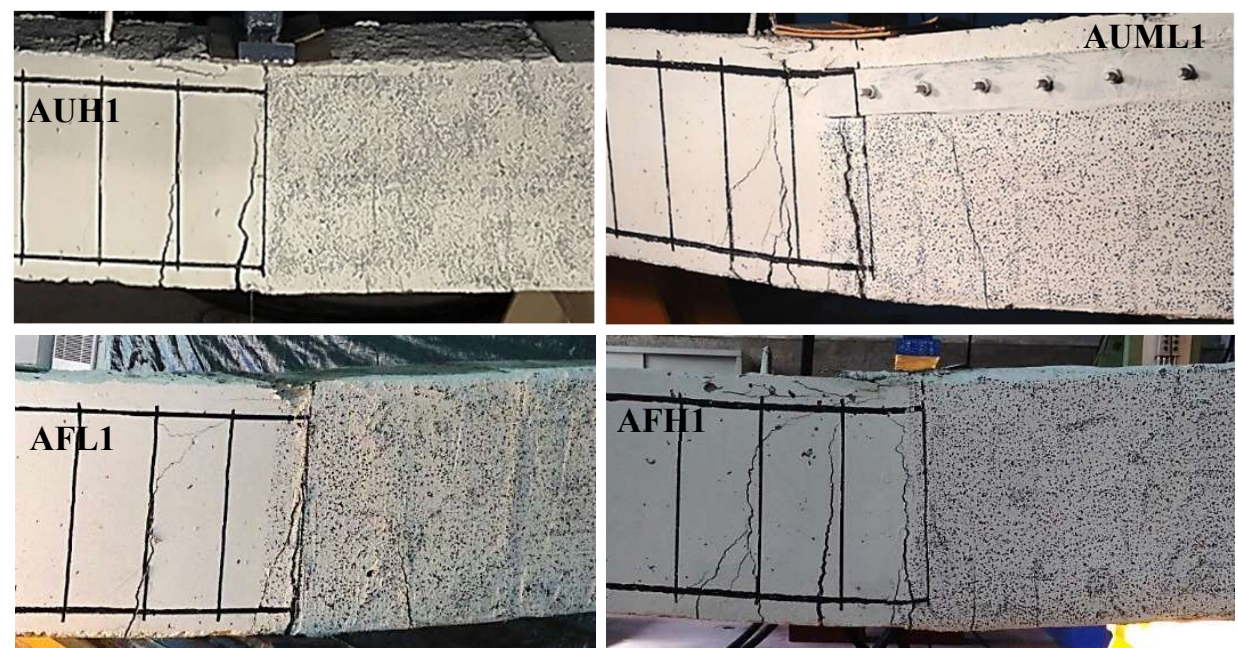

Figure 8: Failure modes of the SRG-strengthened specimens of Group A

The U-wrapped SRG strengthened beams of Group B (BUL1 and BLU2, Table 1) both failed

247 in shear (Fig. 9). The general mode of failure observed was the detachment of the composite

248 system at the interface between the UHTSS textile and the mortar and/or at the interface

249 between the mortar and the concrete substrate, with damage of the external face of the concrete 
The beam with the single-layered U-wrapped SRG jacket (BUL1, Table 1) failed suddenly

252 when the textile between the mid-point of the shear-critical region and the loading point was

253 detached. The state of the critical region of the beam at the end of the test and after exposing

254 the substrate, is shown in Figs. 9a and 9b, respectively. It is observed that only a single shear

255 crack formed, having the same inclination as that in the original beam B0 (see Fig. 7). In case

256 of the two-layered U-wrapped SRG jacketed beam (BUL2, Table 1), the detachment of the

257 composite system occurred at two stages. First, part of the textile placed between the support

258 and the mid-point of the critical region was detached. The beam continued to carry load and, at

259 a later stage, the textile between the mid-point of the critical span and the loading point was

260 detached. Fig. 9c shows the BUL2 beam at the end of the test. Again, as shown in Fig. 9d, one

261 single crack formed with the same inclination as the crack in the original beam B0 (see Fig. 7).

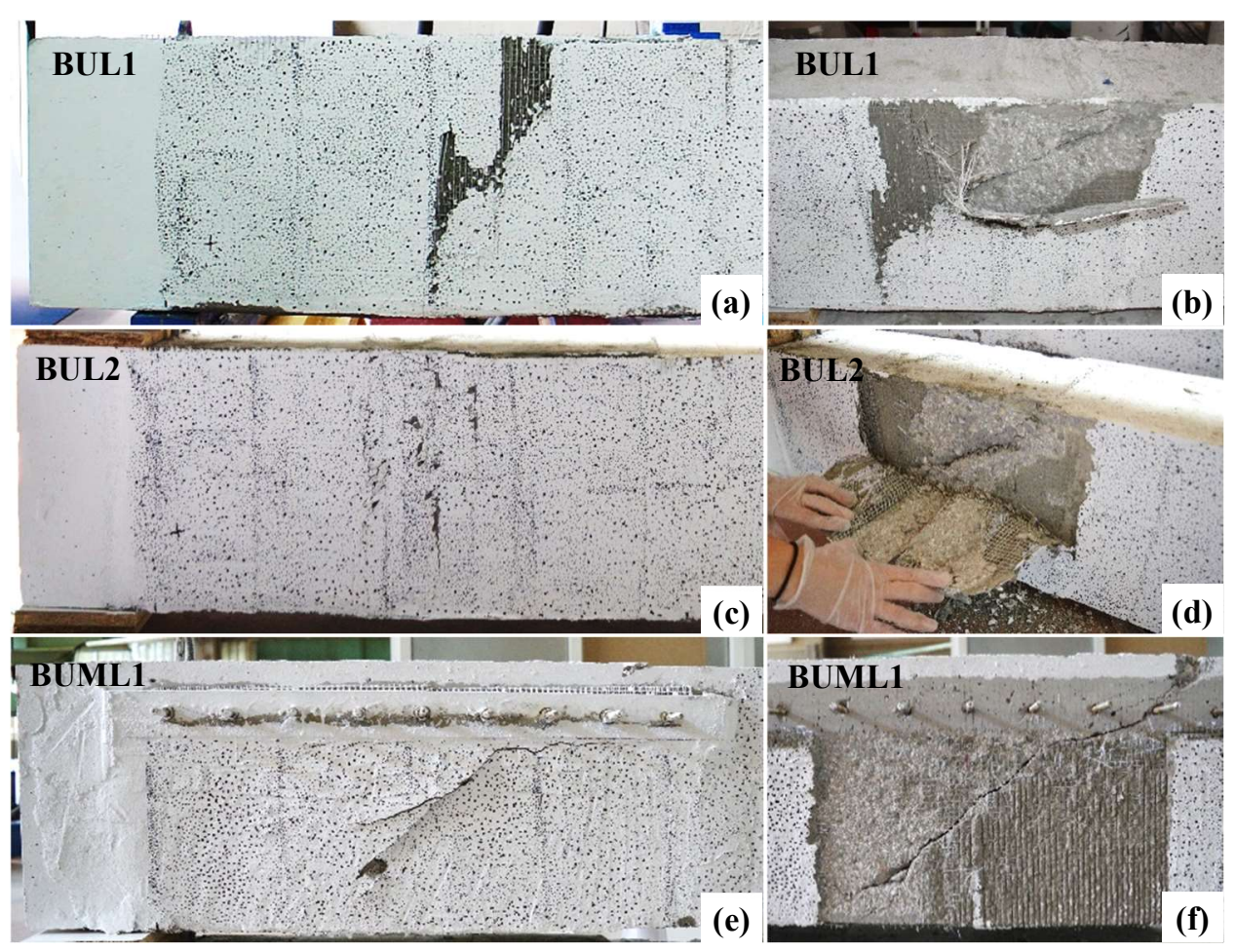

Figure 9: Failure modes of the U-wrapped SRG beams of Group B in the shear-critical span.

After the first stages of loading of the U-wrapped beam with the mechanical anchorage 
shown in Fig. 9e. The existing crack became wider as the load increased. Soon enough the textile detached by forming a new horizontal crack along the bottom side of the metal plate and headed towards the loading point (Fig. 9e). The test was terminated when the inclined crack

271 propagated towards the loading point passed through one of the stud anchors (Fig. 9f). The 272 removal of the jacket and the metal plates revealed that the dominant mode of failure was 273 diagonal tension failure (Fig. 9f) as also observed in the other U-wrapped beams. The SRG 274 jacket remained intact and no damage was visible in the mechanical anchorage system.
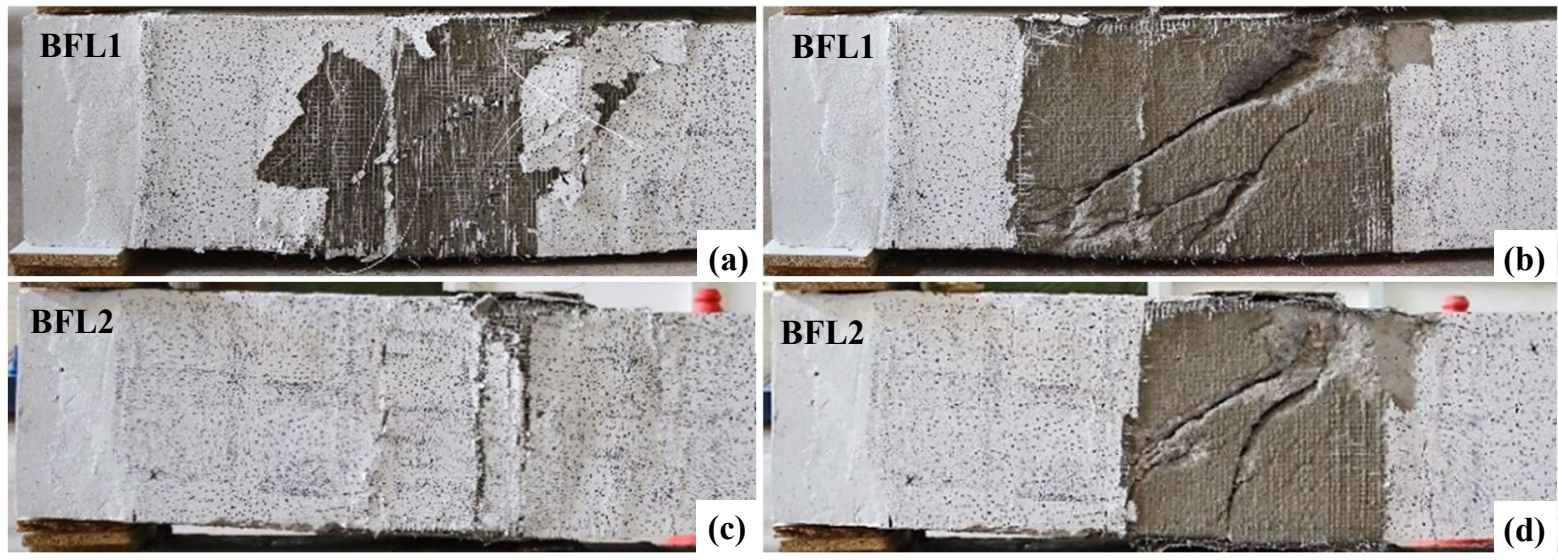

Figure 10: Failure modes of the fully-wrapped SRG beams of Group B in the shear-critical span.

The fully-wrapped SRG beams (BFL1 and BFL2, Table 1) behaved in a more ductile manner compared to the U-wrapped and the original beams. In case of BFL1 beam, a shear-flexure crack formed on the jacket surface within the critical region at the initial stage of loading. As the load increased, damage localized within the inclined area bounded between the loading point and a $150 \mathrm{~mm}$ distance from the support, until the external surface of the SRG jacket was heavily cracked (Fig. 10a). At this stage, the beam could not sustain any additional load, but it continued to deform due to passive confinement provided by the SRG jacket. The beam exhibited a ductile behaviour up to the point where gradual rupture of the cords initiated at the upper and bottom sharp edges on both beam faces. The beam failed due to debonding of the textile in the anchorage region (i.e. the region where the end of the fabric overlapped with the 
beginning of the textile) next to the applied point load. The cracking pattern of beam BFL1 was

290 different from that of the U-wrapped beams and more flexure-shear cracks were observed as shown in Fig. 10b. Similar to the previous case, beam BFL2 failed in a ductile manner with the internal tensile steel reinforcement reaching yielding. At the initial stage of loading, the first flexural crack appeared in the middle of the SRG jacketed shear span. Subsequently, two more

294 flexural cracks appeared in the opposite side of the critical shear span (i.e. the un-strengthened 295 side of the beam) next to the applied point load. As the load increased, no additional flexural 296 cracks were developed, whereas the existing ones became wider. The confinement provided by two-layered SRG jackets could significantly increase the deflection capacity of the beam, and therefore, the beam managed to sustain the load applied after yielding. The rupture of the cords occurred gradually, and it was mainly concentrated between the mid-point of the shear span 300 and the point at which the load applied. The beam finally failed when the free end-zone of the 301 textile was detached from the anchorage region next to the applied point load. The flexural cracks developed in the critical shear span are shown in Fig. 10d.

303 The evolution of damage in the SRG jacketed beams of Group B was influenced by the SRG 304 jacket configuration applied, as shown in Fig. 11. Although the U-wrapped SRG jackets could 305 not prevent shear failure, this was delayed until higher levels of loading. It is observed that 306 similar to the control beam (B0), a single inclined crack was appeared in the U-wrapped beams 307 (BUL1, BUL2, BUML1). The response of the SRG jacketed beams was improved substantially 308 when SRG closed-type jackets (i.e. fully-wrapped) were applied. The confinement provided by 309 the one-layered fully-wrapped jacket (BFL1) led to a ductile behaviour upon shear failure with 310 the presence of a multiple shear-flexure cracking pattern (Fig. 11). The two-layered fully311 wrapped SRG jacket (BFL2) improved substantially the response of the original beam by 312 alleviating the deficiencies related to old type detailing. The SRG jacketed beam failed in 313 flexure with flexural cracks formed near the applied point load. 


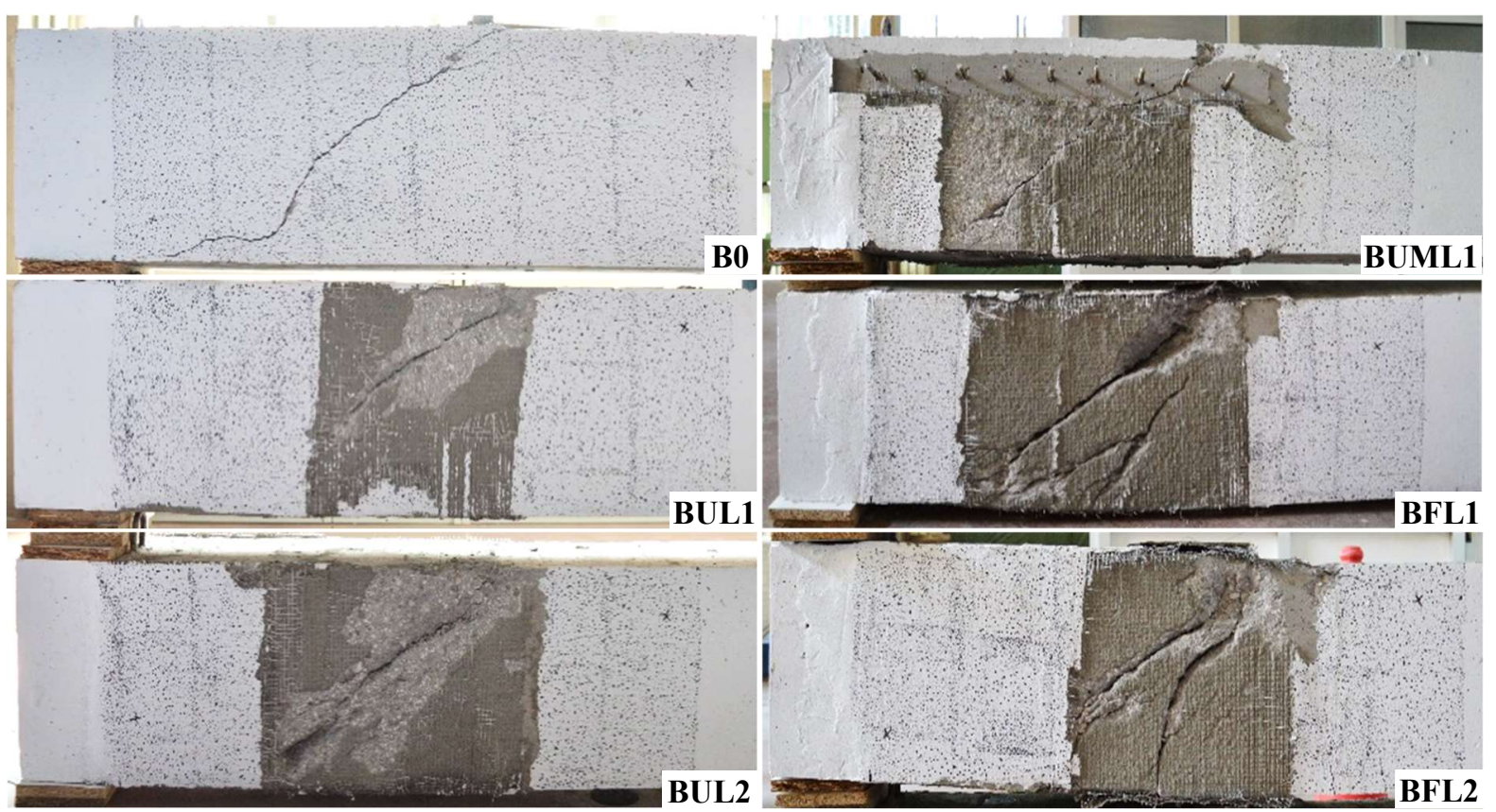

Figure 11: Crack patterns at failure in Group B beams

\subsection{Load deflection curves}

316 The load deflection response curves of Group A and B specimens are presented in Fig. 12. A

317 summary of the test results is also provided in Table 4. The key performance parameters include 318 the peak load $\left(\mathrm{P}_{\max }\right)$ and the corresponding deflection $\left(\delta_{\max }\right)$, the ultimate load at a $20 \%$ drop

319 of the peak load $\left(\mathrm{P}_{\mathrm{u}}\right)$ and the corresponding deflection $\left(\delta_{\mathrm{u}}\right)$, and finally the displacement

320 ductility $\left(\mu_{\delta}\right)$. In case that no descending branch appears in the load-deflection curve, the last

321 point of the curve is considered as the ultimate deflection $\left(\delta_{u}\right)$. The displacement ductility was

322 defined after idealizing the experimental load-deflection curve by a bilinear curve according to

323 the recommendations of ASCE/SEI Standard 41-06 recommendations [42].

324 In general, the results indicate that the SRG shear strengthening intervention could 325 considerably improve the strength and deformation capacity of the control beams. The different 326 jacket configurations applied in Group A beams showed the same level of efficiency in 327 modifying the structural response from brittle to ductile (Fig. 12a). The strength increase at 328 peak load varied between 27.6 to $38.1 \%$, whereas the displacement ductility ranged between 9.1 to 12.3 (Table 4). The lowest increase in the strength and displacement ductility levels was 
observed for the high density U- and fully-wrapped SRG jackets (AUH1 and AFH1). This is

331 because when dense textiles are used in SRG applications, as for example the $4.72 \mathrm{cords} / \mathrm{cm}$

332 density textile, the small gaps between the cords impose difficulties in the penetration of the mortar. Hence, the fact that the cords are not well embedded in the mortar renders the SRG system less efficient. A similar observation was reported by Thermou et al. [19] for retrofitting of RC columns using SRG jacketing. The main conclusion drawn from Group A beams is that in case of lightly reinforced $\mathrm{RC}$ beams $\left(\rho_{1}=0.75 \%\right)$, which are representative of the old construction practice in southern Europe, the lower density $(1.57$ cords/cm) U-wrapped jackets can be very effective in preventing shear failure and modifying the response from brittle to ductile.

The effect of the type of the SRG jacket on the load-deflection response of Group B beams is shown in Fig. 12b. The control beam (B0) failed by diagonal tension failure at a peak load of $105.6 \mathrm{kN}$ (Table 4). The single- and doubled-layered U-wrapped beams (BUL1, BUL2) as well as the single-layered U-wrapped beam with the mechanical anchorage (BUML1) failed in shear at peak loads of 216.7, 221.1 and $225.7 \mathrm{kN}$, respectively (Table 4). The increase in the strength of BUL1, BUL2 and BUML1 beams compared to the control beam (B0) at peak load was 105, 110 and $114 \%$, respectively. The deflection increase at ultimate load was 73,55 and $77 \%$ for BUL1, BUL2 and BUML1 beams, respectively. As observed, the U-wrapped SRG jacket with 348 the mechanical anchorage (BUML1) exhibited the highest load and deflection increase amongst 349 the U-wrapped jackets. This is mainly attributed to the presence of the mechanical anchorage 350 which kept the jacket in place for a higher sustained load compared to the other two U-wrapped 351 SRG jackets (i.e. BUL1, BUL2) and thus contributed further to the resistance of the beam. It can be noted that the single-layered fully-wrapped SRG jacket (BFL1) reached the same peak load as the single-layered U-wrapped SRG jacket with the mechanical anchorage (BUML1) but 354 presented a more ductile post-peak load-deflection response. The fully-wrapped jacketed beam 
deformed up to $20.7 \mathrm{~mm}$ deflection at ultimate load, which implies that $349 \%$ increase in the

356 deflection capacity (or deformability) was achieved compared to the control beam before failing 357 due to debonding of the textile in the anchorage region. The displacement ductility for BFL1 358 beam was estimated equal to 3.4. Using two-layered fully-wrapped SRG jackets in BFL2 beam 359 could substantially increase the shear strength allowing flexural failure to occur. The peak load 360 in this case was $274.2 \mathrm{kN}$, which corresponds to almost $160 \%$ increase when compared to the 361 control beam (B0). The second layer of full jacket increased the deflection at ultimate to 25.5 $362 \mathrm{~mm}$. The displacement ductility was estimated equal to 3.8 , which is rather satisfying 363 considering the inherent deficiency of the beam.

364 Comparison between the results for BLF1 and BLF2 beams shows that increasing the 365 number of SRG layers had a limited effect (around 10\%) on the ductility of the specimens, 366 while it could considerably increase the maximum strength and deflection capacity of the 367 specimens (up to 23\%). The results in Table 4 also indicate that SRG jacketing was more 368 efficient in increasing the deformation capacity and ductility of the beams with lower 369 longitudinal reinforcement ratio (i.e. Group A). However, the effect of SRG jacketing on 370 improving the maximum strength was more pronounced for the beam elements with higher 371 longitudinal reinforcement ratio (i.e. Group B).

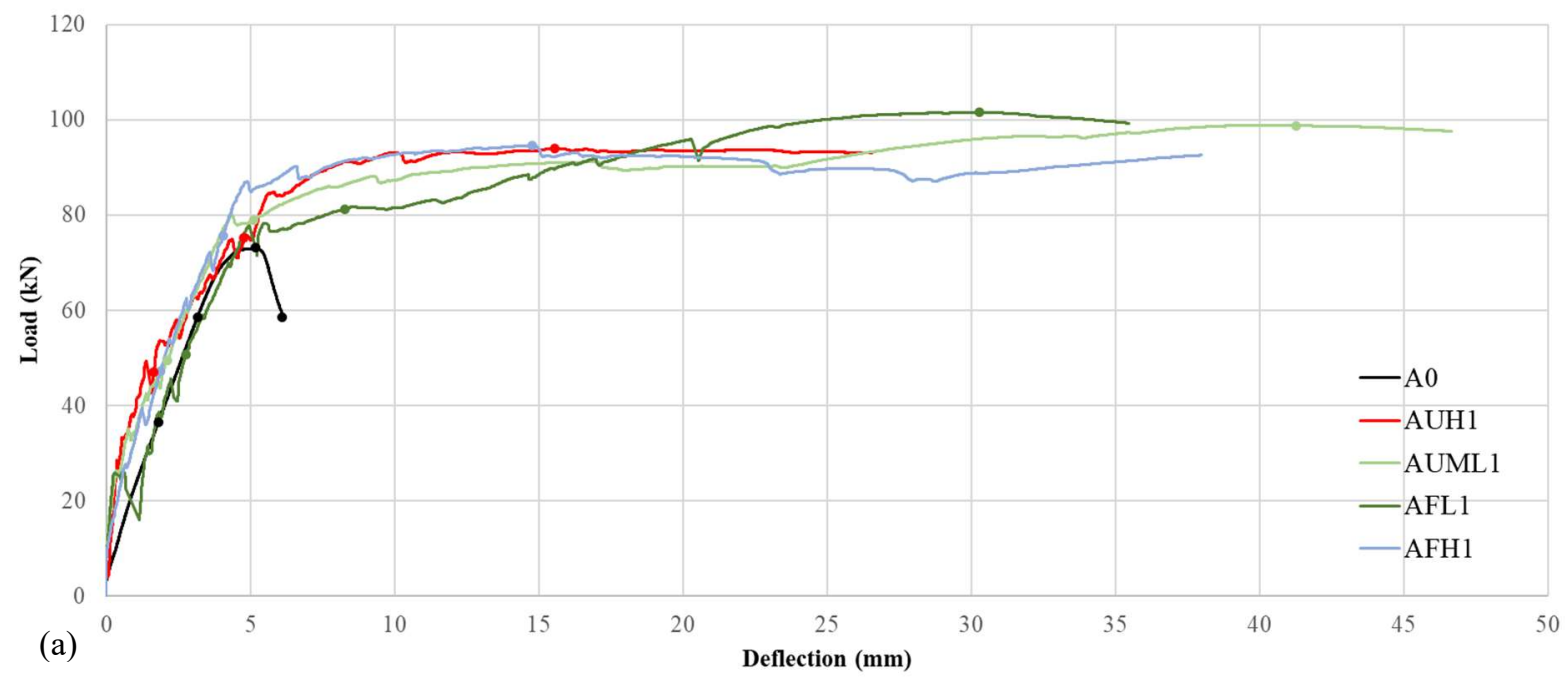




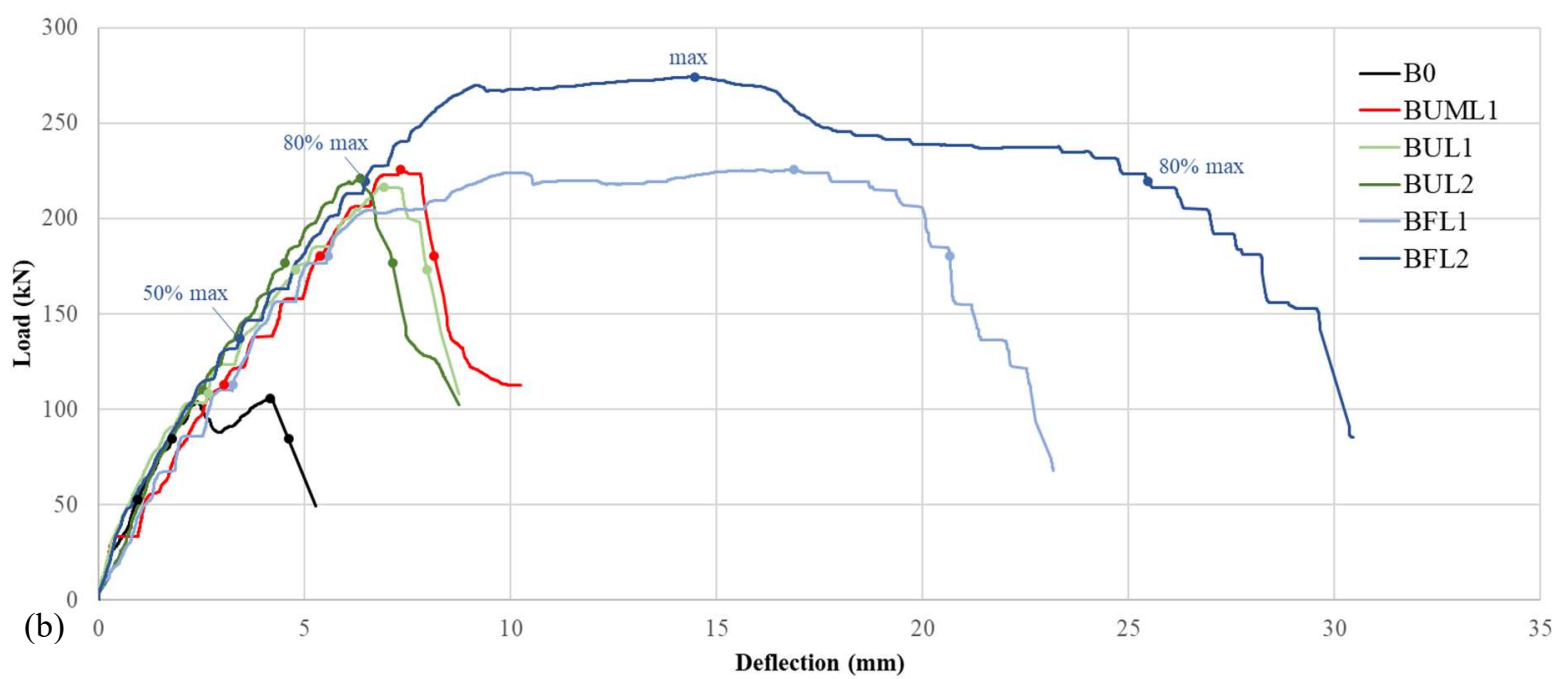

Figure 12: Load-deflection curves for (a) Group A; (b) Group B beams.

Table 4: Summary of test results

\begin{tabular}{|c|c|c|c|c|c|c|c|c|c|}
\hline Group & Name & $\begin{array}{l}\mathbf{P}_{\max } \\
(\mathbf{k N})\end{array}$ & $\begin{array}{c}\mathbf{P}_{\mathbf{u}} \\
(\mathbf{k N})\end{array}$ & $\begin{array}{c}\delta_{\max } \\
(\mathbf{m m})\end{array}$ & $\begin{array}{c}\boldsymbol{\delta}_{\mathbf{u}} \\
(\mathbf{m m})\end{array}$ & $\begin{array}{c}\text { Strength } \\
\text { increase at } \\
\text { peak }(\%)\end{array}$ & $\begin{array}{c}\text { Deflection } \\
\text { increase at } \\
\text { ultimate } \\
(\%)\end{array}$ & $\begin{array}{c}\text { Ductility } \\
\mu_{\delta}\end{array}$ & Failure mode \\
\hline \multirow{5}{*}{ 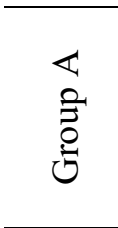 } & A0 & 73.6 & 58.9 & 5.3 & 6.2 & - & - & - & Shear \\
\hline & AUH1 & 93.9 & 93.0 & 15.5 & 26.5 & 27.6 & 326.0 & 9.1 & Flexural \\
\hline & AUML1 & 98.8 & 97.6 & 41.3 & 46.7 & 34.3 & 649.3 & 12.3 & Flexural \\
\hline & AFL1 & 101.6 & 99.4 & 29.2 & 34.4 & 38.1 & 452.5 & 12.1 & Flexural \\
\hline & AFH1 & 94.6 & 92.6 & 14.8 & 38.0 & 28.5 & 510.0 & 10.7 & Flexural \\
\hline \multirow{6}{*}{$\begin{array}{l}\infty \\
\vdots \\
0 \\
0\end{array}$} & B0 & 105.6 & 84.5 & 4.2 & 4.6 & - & - & - & Shear \\
\hline & BUL1 & 216.7 & 173.3 & 6.9 & 8.0 & 105.2 & 73.3 & - & Shear \\
\hline & BUL2 & 221.1 & 176.9 & 6.4 & 7.1 & 109.5 & 55.0 & - & Shear \\
\hline & BUML1 & 225.7 & 180.5 & 7.3 & 8.1 & 113.8 & 77.0 & - & Shear \\
\hline & BFL1 & 225.4 & 180.4 & 16.9 & 20.7 & 113.5 & 349.1 & 3.4 & Shear/Flexural \\
\hline & BFL2 & 274.2 & 219.3 & 14.5 & 25.5 & 159.7 & 453.5 & 3.8 & Flexural \\
\hline
\end{tabular}

\subsection{Evolution of damage based on Digital Image Correlation}

377 As described previously, the additional measurement technique of Digital Image Correlation

378 (DIC) was applied on all specimens by painting a speckle pattern on the shear critical region

379 (area of interest - AOI) of each beam. During testing, a DSLR camera captured high-resolution

380 images of the AOI at given displacement intervals and these images were postprocessed for

381 producing strain contours at preselected characteristic points on the load-displacement response

382 curve. The characteristic points were selected to represent $50 \%, 80 \%$ and $100 \%$ of the peak 
load (ascending branch) as well as $20 \%$ drop of peak load in the descending branch (see Fig.

384 12). The results were used to demonstrate the evolution of damage on the AOI surface in terms of horizontal $\left(\varepsilon_{\mathrm{x}}\right)$ and vertical $\left(\varepsilon_{\mathrm{y}}\right)$ strain distribution.

386 Figure 13 shows the strain evolution of the control specimen B0. It is observed that minor 387 flexural cracks started to develop on the bottom edge of the beam up to the attainment of the 388 peak load when the localized diagonal shear crack was formed. At that point, the longitudinal 389 strain $\left(\varepsilon_{\mathrm{x}}\right)$ reached about $1 \%$, substantially lower than the reinforcement yielding point (about $3902.5 \%$ ). It is notable that a second shear crack also started to develop parallel to the major one; 391 however, it could not fully form due to the brittle shear failure (no descending branch was 392 captured in this case). It was confirmed that the behaviour of the control beam B0 fully 393 corresponds to the typical textbook shear failure type.

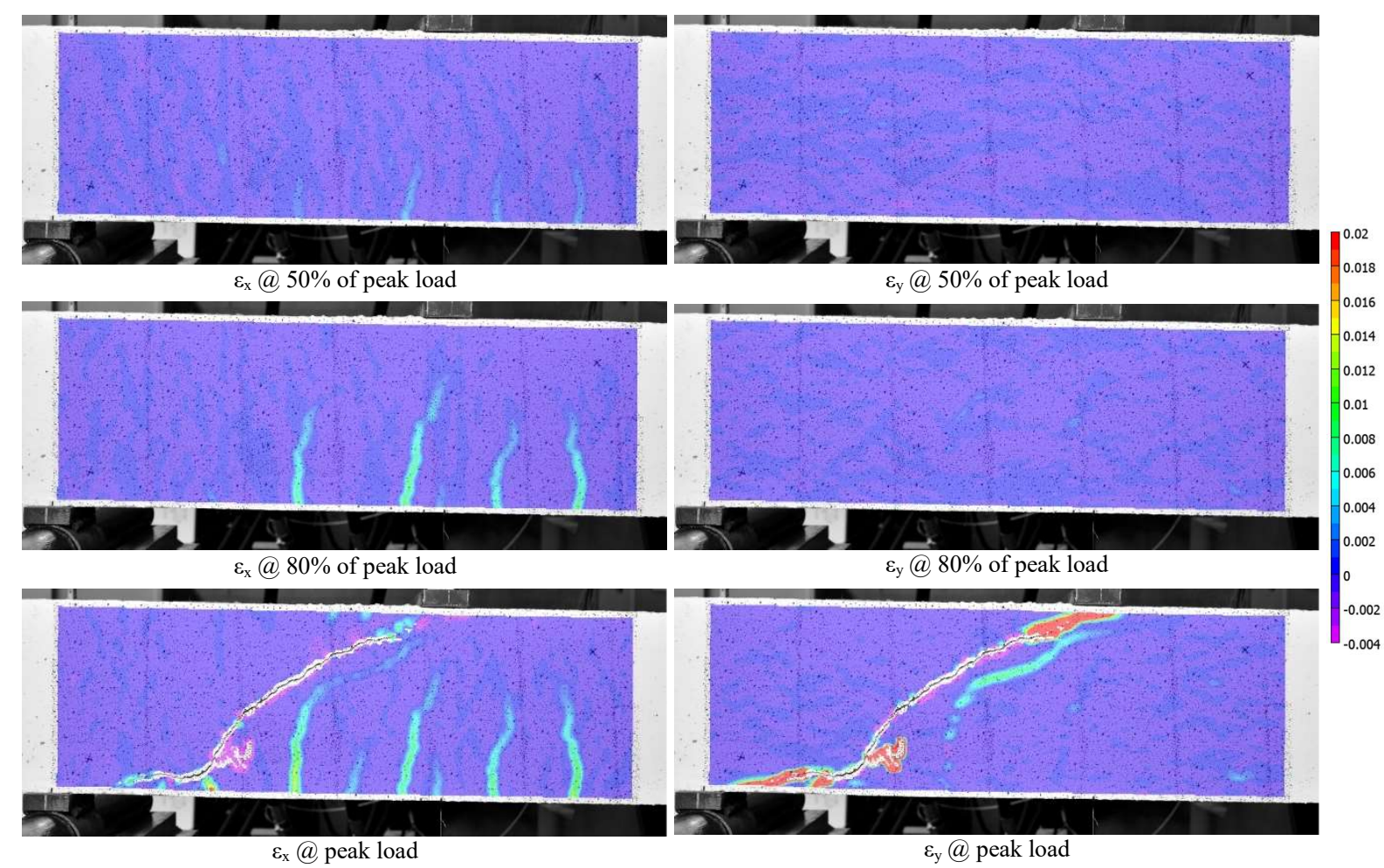

Figure 13: Strain evolution for beam B0 using DIC

The strain evolution of the U-wrapped specimen with single layer (BUL1) is depicted in Fig.

397 14. In this case, the flexural cracks sustained larger longitudinal strains (well over 2\%o) at the 
peak load, where also an inclined yet diffused cracking pattern appeared due to the presence of

399 the SRG U-wrap. This justifies the increased shear strength already recorded during testing for 400 this type of SRG jacketing. For the mechanical anchorage (BUML1) and double-layer U401 wrapped (BUL2) specimens, this diffusion was wider, with less inclined straining (i.e. 402 longitudinal strains only) observed, especially for the latter case.

403
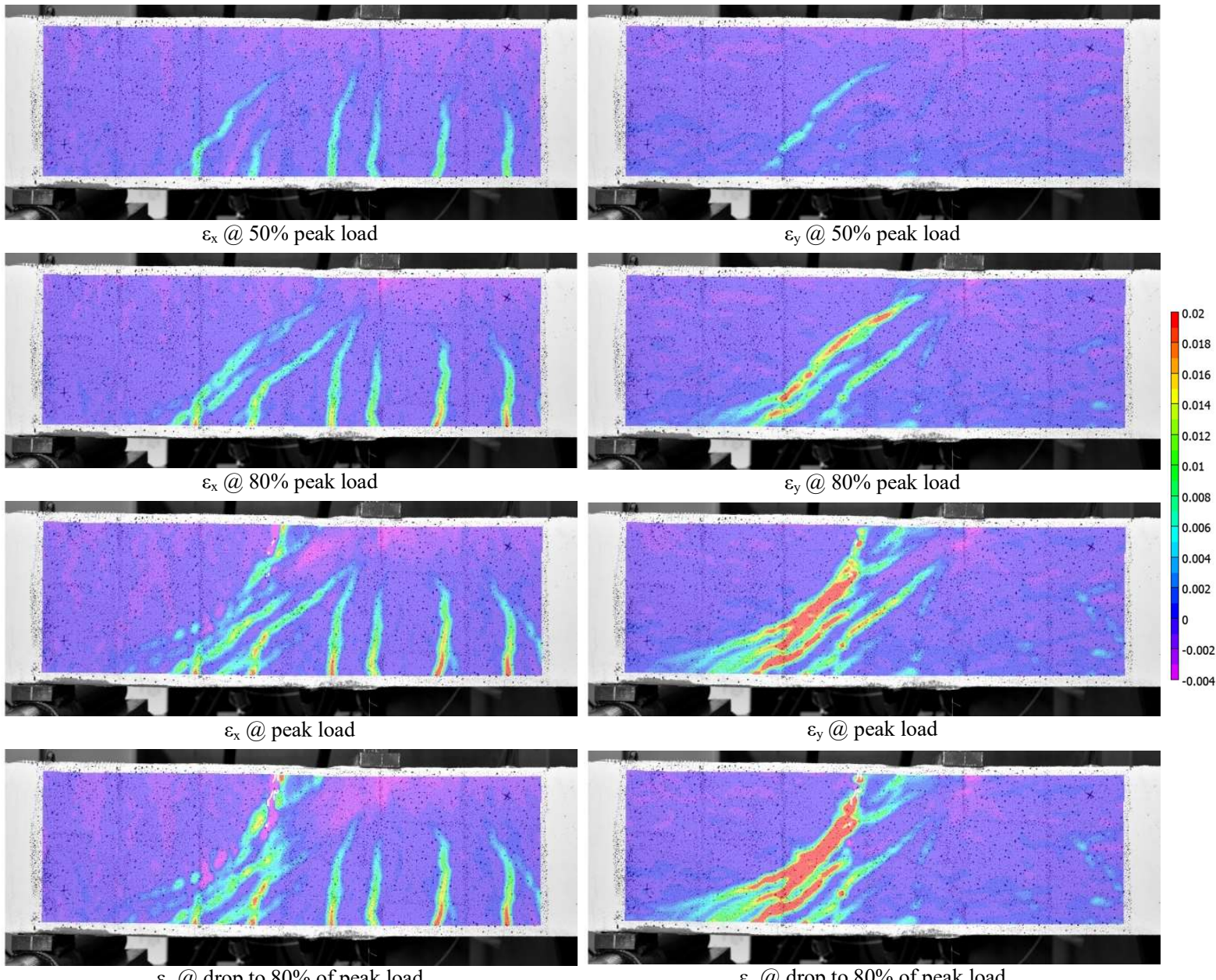

$\varepsilon_{\mathrm{x}}$ (a) drop to $80 \%$ of peak load

$\varepsilon_{\mathrm{y}} @$ drop to $80 \%$ of peak load

404

405

406

407

408

409

410

Figure 14: Strain evolution for beam BUL1 using DIC

Finally, for the fully-wrapped cases (BFL1 and BFL2), the strain evolution on the AOI surface shows that the SRG layer(s) completely prevented the development of diagonal straining of the steel material (see Fig 15). It is observed that strains were strongly diffused only in the longitudinal direction and the failure pattern clearly corresponded to the rupture of the steel cords. 

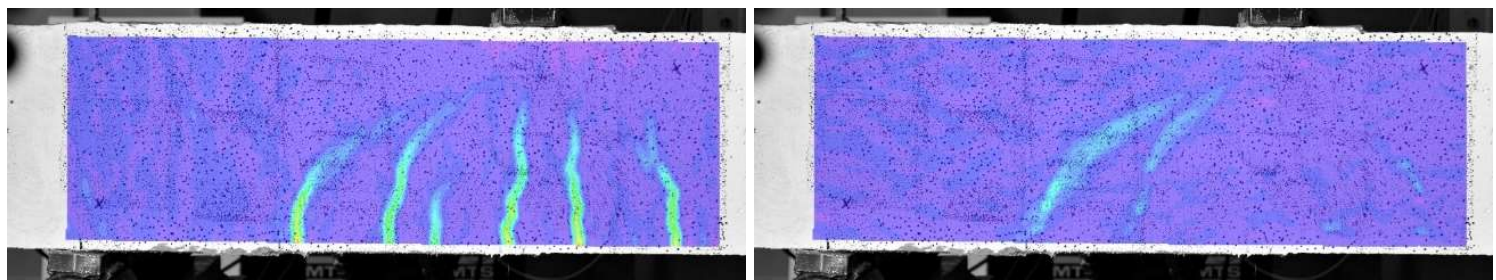

$\varepsilon_{\mathrm{x}} @ 50 \%$ peak load

$\varepsilon_{\mathrm{y}} @ 50 \%$ peak load

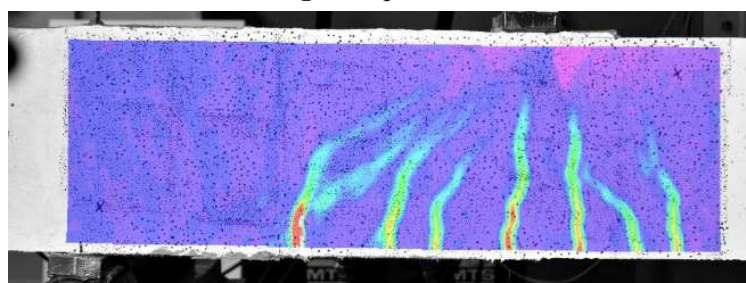

$\varepsilon_{\mathrm{x}} @ 80 \%$ peak load
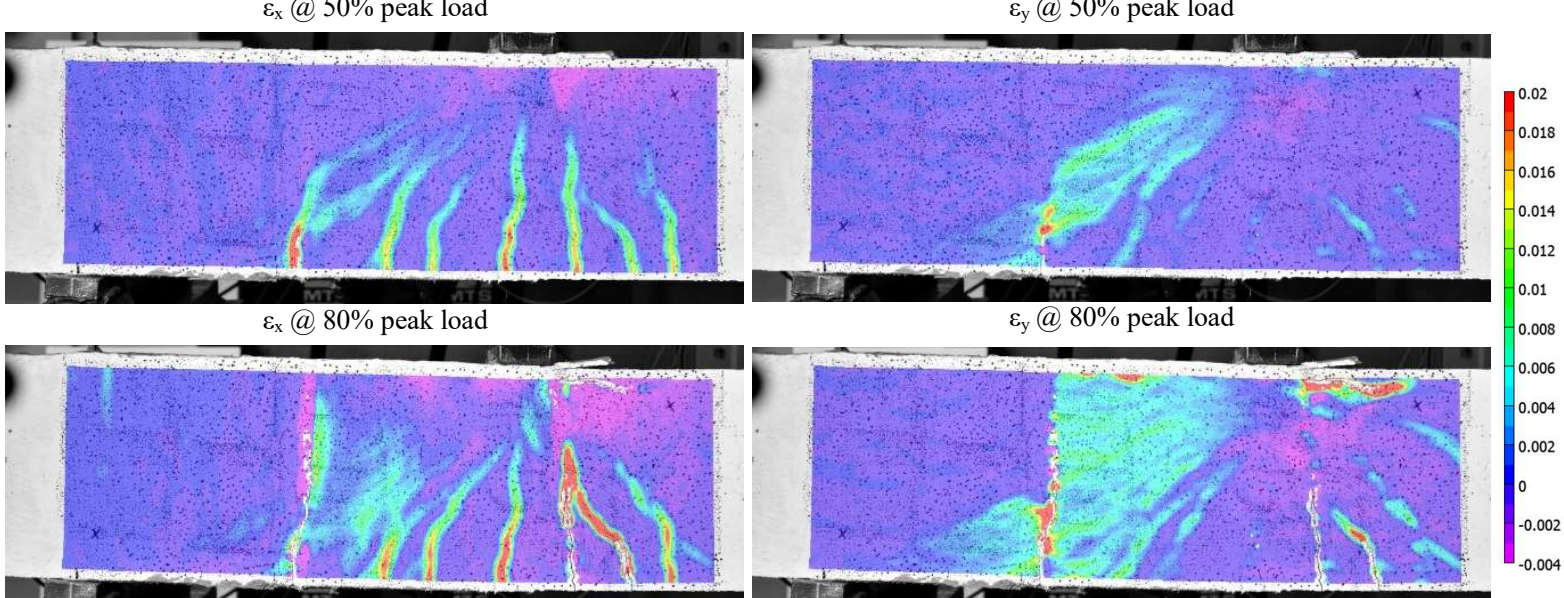

$\varepsilon_{\mathrm{x}} @$ peak load

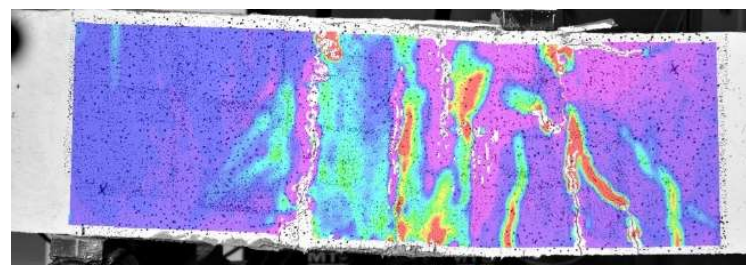

$\varepsilon_{\mathrm{x}} @$ drop to $80 \%$ of peak load $\varepsilon_{\mathrm{y}} @$ peak load

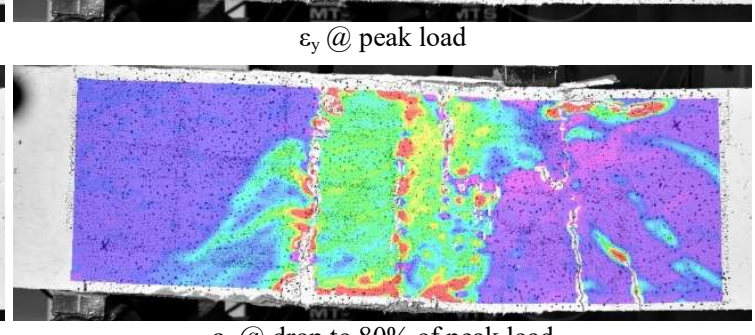

$\varepsilon_{\mathrm{y}} @$ drop to $80 \%$ of peak load

Figure 15: Strain evolution for beam BFL2 using DIC

\section{Comparison of experimental results to analytical predictions}

\subsection{Shear resistance of the SRG jacketed beams}

The total shear strength of SRG jacketed RC beams, $\mathrm{V}_{\text {shear, }}$ comprises shear strength contributions from concrete, $\left(\mathrm{V}_{\mathrm{c}}\right)$, steel stirrups, $\left(\mathrm{V}_{\mathrm{s}}\right)$, and $\mathrm{SRG}$ jacket, $\left(\mathrm{V}_{\mathrm{SRG}}\right)$ :

$$
V_{\text {shear }}=V_{c}+V_{s}+V_{S R G} \leq V_{R d, \text { max }}
$$

$\mathrm{V}_{\text {shear }}$ estimated according to Eq. (1) shall not exceed the limit value for shear, $V_{\mathrm{Rd} \text {,max }}$, which corresponds to crushing of the diagonal compression struts in the web of the member [43]. Since the studied beams did not contain any stirrups in the critical shear span, the term $\mathrm{V}_{\mathrm{s}}$ can be neglected from Eq. (1). The shear strength contribution from concrete, $V_{c}$, is calculated herein by using the EC2 [43] and ACI 318 [44] design guidelines: 


$$
\begin{aligned}
& V_{c}^{E C 2}=0.12 \cdot k \cdot\left(100 \cdot \rho_{l} \cdot f_{c}\right)^{1 / 3} \cdot b_{w} \cdot d \geq 0.035 \cdot k^{3 / 2} \cdot f_{c}^{1 / 2} \cdot b_{w} \cdot d \\
& V_{c}^{A C I}=0.167 \sqrt{f_{c}} \cdot b_{w} \cdot d
\end{aligned}
$$

426 where $f_{c}$ is the concrete compressive strength, $b_{w}$ is the width of the cross section, $d$ is the depth 427 of the cross section, $\mathrm{k}(=1+\sqrt{ }(200 / \mathrm{d}) \leq 2$ with $\mathrm{d}$ in $\mathrm{mm})$ is a factor that considers the size effect 428 and $\rho_{1}$ is the area ratio of the tensile reinforcement.

Similar to the approach adopted for other externally bonded composite materials (e.g. FRP, FRCM), the shear strength contribution of the SRG jackets is determined following the truss analogy model [e.g. 45-49]. The steel fabric is considered to have an equivalent thickness per unit width and an effective strain, $\varepsilon_{\mathrm{f}, \mathrm{eff}}[14]$. By considering the effects of fibre orientation and assuming a crack pattern, the shear force sustained by the SRG can be calculated as:

$$
V_{S R G}=n \cdot \rho_{f} \cdot b_{w} \cdot h_{f} \cdot \varepsilon_{f, e f f} \cdot E_{f} \cdot(\cot \theta+\cot \alpha) \cdot \sin \alpha
$$

where $\mathrm{n}$ is the number of textile layers applied; $\rho_{\mathrm{f}}\left(=2 \cdot \mathrm{t}_{\mathrm{f}} / \mathrm{b}_{\mathrm{w}}\right)$ is the SRG web reinforcement ratio for a single layer; $b_{w}$ is the width of the cross section; $h_{f}$ is the effective depth of the jacket taken as $(\mathrm{h}-0.1 \mathrm{~d}) \approx 0.9 \mathrm{~d}$ ( $\mathrm{h}$ and $\mathrm{d}$ are the height and the effective depth of the cross section, respectively) for full-depth SRG jackets; $\varepsilon_{\mathrm{f}, \mathrm{eff}}$ is the effective strain in the cords; $\mathrm{E}_{\mathrm{f}}$ is the elastic modulus of the SRG fabric; $\alpha$ is the angle between the fibres and the beam axis perpendicular to the shear force; and $\theta$ is the angle between the concrete compression strut and the beam axis 441 perpendicular to the shear force.

442 Depending on whether the textile will be applied in strips of width $b_{f}$ at a longitudinal 443 distance $\mathrm{s}_{\mathrm{f}}$ or as a continuous fabric with an equivalent thickness, $\mathrm{t}_{\mathrm{f}}$, and by considering $\alpha=90^{0}$ 444 (i.e. fibres aligned perpendicular to the horizontal axis) and $\theta=45^{\circ}$ (i.e. the angle between the 445 concrete compression strut and the beam axis perpendicular to the shear force), Eq. (4) is 446 simplified to:

$$
V_{S R G}=2 \cdot n \cdot t_{f} \cdot h_{f} \cdot \varepsilon_{f, e f f} \cdot E_{f} \text { for continuous fabric }
$$




$$
V_{S R G}=2 \cdot n \cdot t_{f} \cdot h_{f} \cdot \frac{b_{f}}{s_{f}} \cdot \varepsilon_{f, e f f} \cdot E_{f} \text { for strips }
$$

In Eqs. $(4,5)$, the effective strain, $\varepsilon_{\text {f,eff, }}$ corresponds to a fraction of the rupture strain for the cords, $\varepsilon_{\mathrm{fu}}$, and is used to account for the non-uniform distribution of stress in the textile intersecting the shear crack and for the reduction of SRG strength due to bending of the fibres at the corners of the cross section. The strain efficiency factor $k_{\varepsilon}\left(=\varepsilon_{f, \text { eff }} / \varepsilon_{\mathrm{fu}}<1\right)$ is implemented for estimating the effective strain, $\varepsilon_{\mathrm{f}, \mathrm{eff}}$.

Different values for $\mathrm{k}_{\varepsilon}$ have been suggested by various researchers and code provisions. Based on an experimental study on carbon TRM jackets, Triantafillou and Papanikolaou [24] concluded that $\varepsilon_{\text {f,eff }}$ corresponds to approximately $50 \%$ of the ultimate strain, $\varepsilon_{\mathrm{fu}}$, of the cords. In a different study, by investigating experimentally the performance of RC beams shear strengthened with various TRM jacketing systems, Escrig et al. [34] proposed a methodology for estimating TRM contribution to the shear capacity based on the following expressions for the effective strain, $\varepsilon_{\mathrm{f}, \mathrm{eff}}$ :

$$
\varepsilon_{f, e f f}=0.035 \cdot\left(\frac{f_{c}^{2 / 3}}{n \cdot E_{f} \cdot \rho_{f}}\right)^{0.65} \cdot \varepsilon_{f u} \text { fully wrapped }
$$

$$
\varepsilon_{f, e f f}=0.020 \cdot\left(\frac{f_{c}^{2 / 3}}{n \cdot E_{f} \cdot \rho_{f}}\right)^{0.55} \cdot \varepsilon_{f u} \text { side bonded or U-wrapped }
$$

where $f_{c}($ in $\mathrm{MPa})$ is the concrete compressive strength, $\varepsilon_{\mathrm{fu}}$ is the strain at failure, $\mathrm{E}_{\mathrm{f}}(\mathrm{in} \mathrm{GPa}$ ) is the elastic modulus of the textile, and $\rho_{\mathrm{f}}$ is the web reinforcement ratio for a single SRG layer. The definition of the modulus of elasticity and the effective strain adopted by the ACI 5499R-13 [46] for the design of externally bonded FRCM systems are based on the behaviour of the cracked composite material. For the case of effective strain of the SRG composite, $\varepsilon_{\mathrm{f}, \mathrm{eff}}^{*}$, an upper limit of 0.004 is used in this study [46]. The modulus of elasticity of the SRG composite, 

defined by tensile tests of the SRG composite [51].

$472[24,34,46])$ to predict the shear capacity of RC beams strengthen by SRG jackets is 473 investigated compared to the experimental results.

\subsection{Experimental results versus analytical predictions}

476 The experimental shear strength values corresponding to the shear critical region, $V_{\text {shear }}^{\exp }(=$ $\left.477 \quad \mathrm{P}_{\max } \cdot \mathrm{L}_{2} / \mathrm{L}\right)$; where $\mathrm{L}_{2}(=1.1 \mathrm{~m})$ is the longer span and $\mathrm{L}(=1.8 \mathrm{~m})$ is the distance between the 478 supports, are presented in Table 5 for all tested specimens (column (3)). The shear strength 479 contributions from concrete, $\mathrm{V}_{\mathrm{c}}$ (Eqs. (2) and (3)), and SRG jacket, $\mathrm{V}_{\mathrm{SRG}}$ (Eq. 5a), are also given 480 in Table 5 (Columns (7)-(11)). $\mathrm{V}_{\text {SRG }}$ and consequently $\mathrm{V}_{\text {shear }}$ are calculated by adopting the 481 three alternative definitions for effective strain, $\varepsilon_{\text {f,eff, }}$ as discussed in the previous section. The

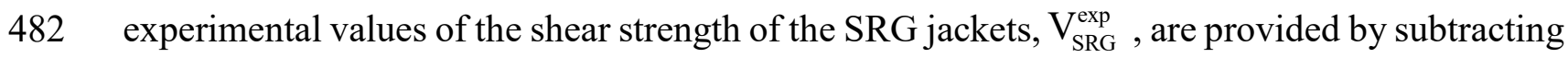
483 the shear strength of the control specimen, $V_{c}^{\text {exp }}$, from the shear strength of the SRG jacketed 484 beams, $V_{\text {shear }}^{\text {exp }}\left(\right.$ see column (4) in Table 5). The experimental values of the effective strain, $\varepsilon_{f, \text { eff }}^{\text {exp }}$, 485 are calculated according to column (6) in Table 5:

$$
\varepsilon_{f, e f f}^{\exp }=\frac{V_{\text {shear }}^{\text {exp }}-V_{c}^{\text {exp }}}{2 \cdot n \cdot t_{f} \cdot h_{f} \cdot \varepsilon_{f, e f f} \cdot E_{f}}
$$

487 where $\mathrm{n}$ is the number of textile layers applied; $\mathrm{t}_{\mathrm{f}}$ is the equivalent thickness of the textile; $\mathrm{h}_{\mathrm{f}}$ is 488 the effective depth of the jacket; $\varepsilon_{\mathrm{f}, \mathrm{eff}}$ is the effective strain; $\mathrm{E}_{\mathrm{f}}$ is the elastic modulus of the 489 textile; and $V_{\text {SRG }}^{\text {exp }}$ and $V_{c}^{\text {exp }}$ correspond to the experimental values of the shear strength of the SRG jackets and the control specimen, respectively. The same expression can be used for 
491 calculating the effective strain of the SRG composite, $\varepsilon_{\mathrm{f}, \mathrm{eff}}^{*}$, if the modulus of elasticity of the 492 SRG composite, $\mathrm{E}_{\mathrm{f}}^{*}$, is used ( column (5) in Table 5).

493 The experimental and the predicted normalized shear stress provided by the SRG system are 494 calculated from:

$$
\begin{gathered}
v_{S R G}^{\exp }=\frac{V_{S R G}^{\exp }}{b_{w} \cdot d \cdot f_{c}} \\
v_{S R G}=\frac{V_{S R G}}{b_{w} \cdot d \cdot f_{c}}
\end{gathered}
$$

where $b_{w}$ is the width of the cross section, $d$ is the depth of the cross section, $f_{c}$ is the concrete the shear strength of the SRG jackets, respectively.

Fig. 16 compares the experimental values of the normalized shear stress, $v_{\mathrm{SRG}}^{\mathrm{exp}}$, with the predicted ones, $v_{S R G}$, for the three different definitions of the effective strain, $\varepsilon_{\mathrm{f}, \text { eff, }}$ adopted herein. Based on the observed mode of failure, the beam test data are divided into three categories; no damage to the textile for beams in Group A, debonding of the textile for the Uwrapped Group B beams, and rupture of the textile for the fully-wrapped beams of Group B.

The $45^{\circ}$ linear lines in Fig. 13 can provide direct insight on whether the adopted model underestimates or overestimates the predicted values for the shear stress, $v_{S R G}$; and therefore,

508 determine how safe is to use these particular models. In case of Group A beams, where no 509 damage was observed in the textile, $v_{S R G}$ is overestimated for all the three definitions of the 510 effective strain adopted in this study (see Fig. 13a-c). The ACI 549-9R-13 [46] and Escrig et al. 511 [34] models generally provided safe results, since the predicted values were lower than the 512 experimental ones for the beams that failed due to debonding and rupture of the textile (see the 
513 points plotted above the linear line in Figs. 13a and 13c). For the same modes of failure, the

514 Triantafillou and Papanikolaou [24] model provided both safe and unsafe predictions as 515 illustrated in Fig. 13(b).

516 The accuracy of the adopted models is further investigated by employing statistical indices 517 such as the mean value (AVR), the standard deviation (STD), the coefficient of variation 518 (COV=STD/AVR) and also the average absolute error (AAE) defined as follows:

$$
A A E=\frac{\sum_{i=1}^{N}\left|\frac{\left(v_{S R G}\right)_{i}-\left(v_{S R G}^{\exp }\right)_{i}}{\left(v_{S R G}^{\exp }\right)_{i}}\right|}{N}
$$

520 where $\left(v_{S R G}\right)_{i}$ and $\left(v_{S R G}^{\exp }\right)_{i}$ represent the predicted and experimental values of the shear strength

521 and $\mathrm{N}$ corresponds to the total number of beams. Table 6 presents the calculated statistical 522 indices for each model based on the mode of failure observed. The minimum AAE value is 523 observed for the Triantafillou and Papanikolaou [24] model when rupture and debonding are 524 the anticipated modes of failure. For the same modes of failure, the minimum COV corresponds 525 to the Escrig et al. [34] model.

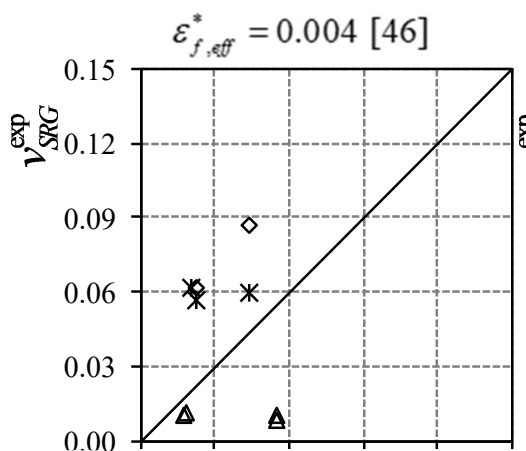

(a) $\begin{array}{cccccc}0.00 & 0.03 & 0.06 & 0.09 & 0.12 & 0.15 \\ v_{S R G}\end{array}$

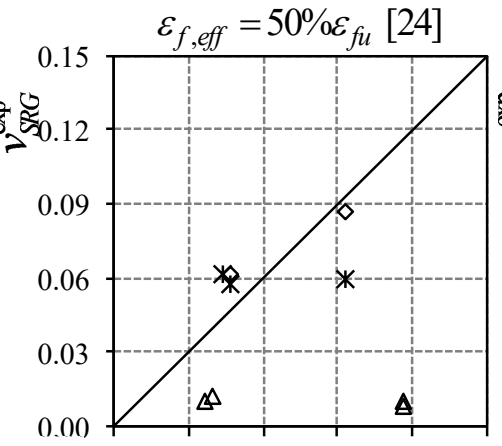

(b) $0.00 \quad 0.03 \quad 0.06 \quad 0.09 \quad 0.12,0.15$

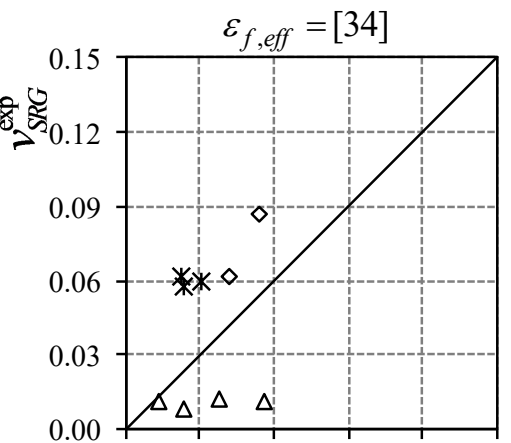

(c) $0.00 \quad 0.03 \quad 0.06 \quad 0.09 \quad 0.12 \begin{array}{lll}0.15 \\ v_{S R G}\end{array}$ $\Delta$ No damage - Group A $\quad *$ Debonding - U-wrapped Group B $\diamond$ Rupture - Fully-wrapped Group B

Figure 16: Comparison between experimental, $\mathrm{v}_{\mathrm{SRG}}^{\mathrm{exp}}$, and predicted, $\mathrm{v}_{\mathrm{SRG}}$, shear strength. 
Table 5: Comparison between experimental and predicted values of shear strength

\begin{tabular}{|c|c|c|c|c|c|c|c|c|c|c|c|c|c|c|}
\hline \multirow{4}{*}{ 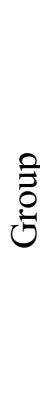 } & \multirow{3}{*}{ 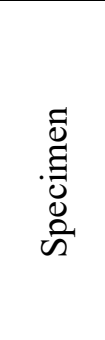 } & \multicolumn{5}{|c|}{ Experimental values } & \multicolumn{8}{|c|}{ Analytical predictions } \\
\hline & & \multirow{2}{*}{$\begin{array}{l}\mathrm{V}_{\mathrm{c}}^{\exp } \\
(\mathrm{kN})\end{array}$} & \multirow{2}{*}{$\begin{array}{l}\mathrm{V}_{\text {shear }}^{\text {exp }} \\
(\mathrm{kN})\end{array}$} & \multirow{2}{*}{$\begin{array}{c}\mathrm{V}_{\mathrm{SRG}}^{\mathrm{exp}} \\
(\mathrm{kN})\end{array}$} & \multirow{2}{*}{$\begin{array}{l}\varepsilon_{\mathrm{f}, \mathrm{eff}}^{*}{ }^{* \operatorname{efp}} \\
\mathrm{x} 10^{3}\end{array}$} & \multirow{2}{*}{$\begin{array}{l}\varepsilon_{\mathrm{f}, \mathrm{eff}}^{\exp } \\
\mathrm{x} 10^{3}\end{array}$} & \multirow{2}{*}{$\begin{array}{l}\mathrm{V}_{\mathrm{c}}^{\mathrm{ACI}} \\
(\mathrm{kN})\end{array}$} & \multirow{2}{*}{$\begin{array}{c}\mathrm{V}_{\mathrm{c}}^{\mathrm{EC} 2} \\
(\mathrm{kN})\end{array}$} & $\varepsilon_{\mathrm{f}, \mathrm{eff}}^{*}[46]$ & $\varepsilon_{\mathrm{f}, \mathrm{eff}}[24]$ & $\varepsilon_{\mathrm{f}, \mathrm{eff}}[34]$ & $\varepsilon_{\mathrm{f}, \mathrm{eff}}^{*}[46]$ & $\varepsilon_{\mathrm{f}, \mathrm{eff}}[24]$ & $\varepsilon_{\mathrm{f}, \mathrm{eff}}[34]$ \\
\hline & & & & & & & & & $\mathrm{V}_{\mathrm{SRG}}(\mathrm{kN})$ & $\mathrm{V}_{\mathrm{SRG}}(\mathrm{kN})$ & $\mathrm{V}_{\mathrm{SRG}}(\mathrm{kN})$ & $\begin{array}{l}V_{\text {shear }} \\
(\mathrm{kN})\end{array}$ & $\begin{array}{l}V_{\text {shear }} \\
(\mathrm{kN})\end{array}$ & $\begin{array}{l}V_{\text {shear }} \\
(\mathrm{kN})\end{array}$ \\
\hline & (1) & (2) & (3) & $(4)=(3)-(2)$ & (5) & (6) & (7) & (8) & (9) & (10) & (11) & $(12)=(7)+(9)$ & $(13)=(8)+(10)$ & $(14)=(8)+(11)$ \\
\hline \multirow{4}{*}{ A } & AUH1 & 47.6 & 60.8 & 13.1 & 0.63 & 0.56 & 47.9 & 27.4 & 83.3 & 176.7 & 35.8 & 131.2 & 204.1 & 63.2 \\
\hline & AUML & 47.6 & 63.9 & 16.3 & 2.55 & 2.25 & 47.9 & 27.4 & 25.6 & 54.3 & 20.1 & 73.5 & 81.8 & 47.6 \\
\hline & AFL1 & 47.6 & 65.8 & 18.1 & 2.61 & 2.31 & 47.9 & 27.4 & 27.8 & 58.9 & 57.3 & 75.7 & 86.3 & 84.7 \\
\hline & AFH1 & 47.6 & 63.9 & 16.3 & 0.78 & 0.69 & 47.9 & 27.4 & 83.3 & 176.7 & 84.1 & 131.2 & 204.1 & 111.6 \\
\hline \multirow{5}{*}{ B } & BUL1 & 68.3 & 146.0 & 71.9 & 10.43 & 9.22 & 43.4 & 39.3 & 27.6 & 58.5 & 30.0 & 70.9 & 97.7 & 69.3 \\
\hline & BUL2 & 68.3 & 140.2 & 74.8 & 5.42 & 4.80 & 43.4 & 39.3 & 55.1 & 116.9 & 38.2 & 98.5 & 156.2 & 77.5 \\
\hline & BUML & 68.3 & 143.1 & 77.6 & 12.11 & 10.71 & 43.4 & 39.3 & 25.6 & 54.3 & 27.9 & 69.0 & 93.6 & 67.1 \\
\hline & BFL1 & 68.3 & 145.9 & 77.6 & 11.25 & 9.95 & 43.4 & 39.3 & 27.6 & 58.5 & 52.5 & 70.9 & 97.7 & 91.8 \\
\hline & BFL2 & 68.3 & 177.4 & 109.1 & 7.92 & 7.00 & 43.4 & 39.3 & 55.1 & 116.9 & 66.9 & 98.5 & 156.2 & 106.2 \\
\hline
\end{tabular}

529

530 
Table 6: Statistical indices for $v_{S R G}^{\exp } / v_{S R G}$

\begin{tabular}{|c|c|c|c|c|c|c|c|c|c|}
\hline \multirow[b]{2}{*}{$\begin{array}{c}\text { Statistical } \\
\text { indices }\end{array}$} & \multicolumn{3}{|c|}{ No damage } & \multicolumn{3}{|c|}{ Debonding } & \multicolumn{3}{|c|}{ Rupture } \\
\hline & $\begin{array}{l}\varepsilon_{\mathrm{f}, \mathrm{eff}}^{*} \\
{[46]}\end{array}$ & $\begin{array}{l}\varepsilon_{\mathrm{f}, \mathrm{eff}} \\
{[24]}\end{array}$ & $\begin{array}{l}\varepsilon_{\mathrm{f}, \mathrm{eff}} \\
{[34]}\end{array}$ & $\begin{array}{l}\varepsilon_{\mathrm{f}, \mathrm{eff}}^{*} \\
{[46]}\end{array}$ & $\begin{array}{l}\varepsilon_{\mathrm{f}, \mathrm{eff}} \\
{[24]}\end{array}$ & $\begin{array}{l}\varepsilon_{\mathrm{f}, \mathrm{eff}} \\
{[34]}\end{array}$ & $\begin{array}{l}\varepsilon_{\mathrm{f}, \mathrm{eff}}^{*} \\
{[46]}\end{array}$ & $\begin{array}{l}\varepsilon_{\mathrm{f}, \mathrm{eff}} \\
{[24]}\end{array}$ & $\begin{array}{c}\varepsilon_{f, \mathrm{eff}} \\
{[34]}\end{array}$ \\
\hline AVR & 3.64 & 7.72 & 3.07 & 0.48 & 1.03 & 0.43 & 0.43 & 0.91 & 0.64 \\
\hline STD & 2.46 & 5.23 & 1.62 & 0.22 & 0.47 & 0.08 & 0.11 & 0.22 & 0.04 \\
\hline $\mathrm{COV}$ & $67.7 \%$ & $67.7 \%$ & $52.7 \%$ & $45.7 \%$ & $45.7 \%$ & $17.9 \%$ & $24.6 \%$ & $24.6 \%$ & $7.0 \%$ \\
\hline AAE & $263.9 \%$ & $671.7 \%$ & $206.8 \%$ & $51.6 \%$ & $35.0 \%$ & $57.1 \%$ & $57.0 \%$ & $15.9 \%$ & $35.5 \%$ \\
\hline
\end{tabular}

For better comparison, the normalized experimental value of the effective strain, $\varepsilon_{\mathrm{f}, \mathrm{eff}}^{\mathrm{exp}} / \varepsilon_{\mathrm{fu}}$, is plotted against the quantity $\rho_{\mathrm{f}} \cdot \mathrm{E}_{\mathrm{f}} / \mathrm{f}_{\mathrm{c}}^{2 / 3}$ in Fig. 17. The term $\rho_{\mathrm{f}} \cdot \mathrm{E}_{\mathrm{f}}$ expresses the axial rigidity of the textile or the composite in case the modulus of elasticity is that of the composite, $\mathrm{E}_{\mathrm{f}}^{*}$. The term $f_{c}^{2 / 3}$ is related to the tensile strength of the concrete, where $f_{c}$ is the compressive strength of concrete. It is shown in Fig. 17 that, similar to observations made for FRP composites [52], $\varepsilon_{\mathrm{f}, \mathrm{eff}}^{\exp } / \varepsilon_{\mathrm{fu}}$ decreases as $\rho_{\mathrm{f}} \cdot \mathrm{E}_{\mathrm{f}} / \mathrm{f}_{\mathrm{c}}^{2 / 3}$ increases. The horizontal line corresponds to $\varepsilon_{\mathrm{f} \text {,eff }}^{\mathrm{exp}} / \varepsilon_{\mathrm{fu}}=50 \%$ [24].

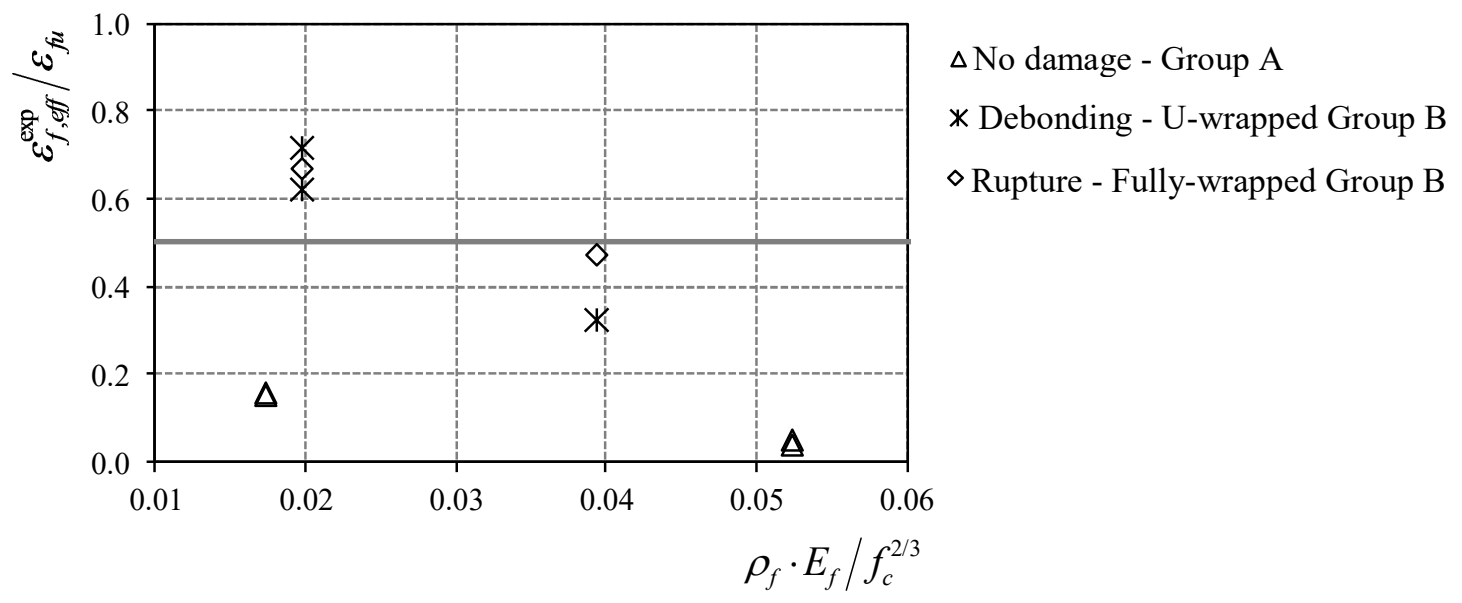

Figure 17: Normalized experimental effective strain, $\varepsilon_{\mathrm{f}, \text { eff }}^{\exp } / \varepsilon_{\mathrm{fu}}$, versus $\rho_{\mathrm{f}} \cdot \mathrm{E}_{\mathrm{f}} / \mathrm{f}_{\mathrm{c}}^{2 / 3}$.

The experimental data were used to derive best fit curves that relate $\varepsilon_{\mathrm{f}, \text { eff }}^{\exp } / \varepsilon_{\mathrm{fu}}$ to $\rho_{\mathrm{f}} \cdot \mathrm{E}_{\mathrm{f}} / \mathrm{f}_{\mathrm{c}}^{2 / 3}$ as presented in Fig. 18. It should be mentioned that the U-wrapped beams with the mechanical 
anchorage (AUML1 and BUML1 in Table 1) were excluded from the utilized data since the objective was to include only specimens where no additional connection measures for the jackets were taken. The following expressions have been derived:

$$
\begin{aligned}
\varepsilon_{f, e f f} & =0.010 \cdot\left(\frac{f_{c}^{2 / 3}}{n \cdot E_{f} \cdot \rho_{f}}\right)^{0.47} \cdot \varepsilon_{f u} \text { no damage in the textile } \\
\varepsilon_{f, e f f}= & 0.015 \cdot\left(\frac{f_{c}^{2 / 3}}{n \cdot E_{f} \cdot \rho_{f}}\right)^{0.94} \cdot \varepsilon_{f u} \text { side bonded or U-wrapped } \\
\varepsilon_{f, e f f} & =0.066 \cdot\left(\frac{f_{c}^{2 / 3}}{n \cdot E_{f} \cdot \rho_{f}}\right)^{0.59} \cdot \varepsilon_{f u} \text { fully wrapped }
\end{aligned}
$$

It should be noted that the above equations are based on limited experimental data and need to be verified by more data before used for practical design purposes. However, the results of this study should prove useful in understanding the influence of key design parameters on the effectiveness of shear strengthening of RC beams using SRG jackets.

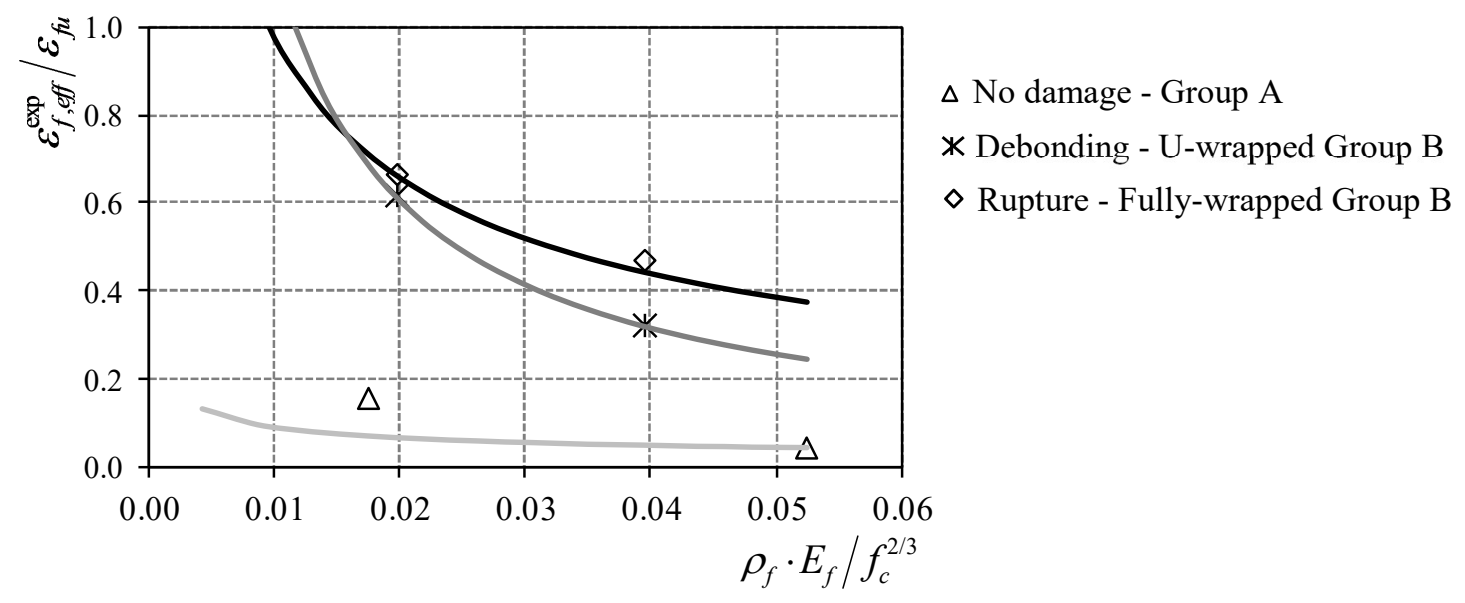

Figure 18: Best fit curves that relate $\varepsilon_{\mathrm{f}, \mathrm{eff}}^{\mathrm{exp}} / \varepsilon_{\mathrm{fu}}$ to $\rho_{\mathrm{f}} \cdot \mathrm{E}_{\mathrm{f}} / \mathrm{f}_{\mathrm{c}}^{2 / 3}$. 


\section{CONCLUSIONS}

An experimental study was carried out to investigate the effectiveness of SRG jacketing as a relatively new composite system for strengthening shear-deficient RC beams. Eleven two-span $\mathrm{RC}$ beams were constructed and classified into two groups according to the arrangement of the internal reinforcement. Two of the beams served as control specimens whereas the rest were strengthened with one- or two-layered U-wrapped, U-wrapped with mechanical anchorage and fully-wrapped SRG jackets. Apart from the jacket configuration, parameters of study were the density of the fabric and the number of layers. Digital Image Correlation (DIC) was applied on all specimens to produce strain contours at several characteristic points on the loaddisplacement response curve. The strain evolution within the critical span and the crack patterns were analysed, while the rupture of the steel cords was verified by the strains diffusion observed in the longitudinal direction. The main conclusions drawn from this study are summarized as follows:

- The different types of SRG jackets applied to the lightly-reinforced Group A beams $\left(\rho_{1}=\right.$ $0.75 \%$ ) could increase the peak load capacity and displacement ductility by up to $38 \%$ and $12 \%$, respectively. In all cases the shear failure was prevented, and the response was modified from brittle to ductile.

- The U-wrapped SRG beams of Group B $\left(\rho_{1}=1.60 \%\right)$ failed in shear due to detachment of the composite system in the shear-critical region. The use of the suggested mechanical anchorage system could keep the SRG jacket in place for a higher sustained load compared to the U-wrapped SRG beams. The average strength and deflection capacity increase of the U-wrapped beams compared to the control beam was $110 \%$ and $70 \%$, respectively.

- The single-layered fully-wrapped SRG jacket applied on Group B beams resulted in a ductile behaviour (displacement ductility $\mu_{\delta}=3.4$ ) upon failure with the presence of multiple shearflexure cracks. The two-layered fully-wrapped SRG jacket modified substantially the 
response of the original member by allowing it to fail in flexure (displacement ductility $\mu_{\delta}=$ 3.8). The maximum strength increased to 114 and $160 \%$ of that of the original shear deficient beam by using single-layered and two-layered fully-wrapped SRG jackets, respectively.

- The experimental values of the shear stress were compared to the predicted ones utilizing the effective strain as defined by Triantafillou and Papanicolaou [24], Escrig et al. [34] and ACI 549-9R-13 [44]. The minimum AAE value was observed for the Triantafillou and Papanikolaou [24] model when rupture and debonding are the anticipated modes of failure.

- Based on the experimental data of current study, new expressions were developed for estimating the effective strain of the SRG jacket using different jacketing systems as a function of the axial rigidity of the SRG textile. However, more experimental data are required to assess the validity of the proposed expressions before they can be widely adopted. The results of this study in general indicate that the SRG jacketing can be considered as a promising strengthening technique for shear-deficient RC beams. Further investigation is deemed necessary on the interaction of internal and externally bonded SRG reinforcement.

\section{ACKNOWLEDGMENTS}

The experimental program was conducted in the Laboratory of Reinforced Concrete and Masonry Structures, Civil Engineering Department, Aristotle University of Thessaloniki. Special thanks are attributed to Interbeton and Kerakoll S.p.A. for providing the materials. This project has received funding from the European Union's Horizon 2020 research and innovation programme under the Marie Skłodowska-Curie grant agreement No. 700863. 


\section{REFERENCES}

[1]. G.E. Thermou, S.J. Pantazopoulou, Assessment indices for the seismic vulnerability of existing RC buildings. Journal of Earthquake Engineering and Structural Dynamics, (2011) 40 (3), 293-313.

[2]. S.J. Pardalopoulos, G.E. Thermou, S.J. Pantazopoulou, Screening Criteria to Identify Brittle RC Structural Failures in Earthquakes. Bulletin of Earthquake Engineering, (2013), 11(2), 607-636.

[3]. G.E. Thermou, M. Psaltakis, Retrofit design methodology for substandard R.C. buildings with torsional sensitivity. Journal of Earthquake Engineering (2018). DOI: $10.1080 / 13632469.2016 .1277569$.

[4]. H. Saadatmanesh, M.R. Ehsani, L. Jin, Repair of earthquake - damaged RC columns with FRP wraps. ACI Struct. J. 94(2) (1997) 206-215.

[5]. F. Seible, M.J.N. Priestley, G.A. Hegemier, Seismic retrofit of RC columns with continuous carbon fiber jackets. ASCE J. of Comp. for Constr. 1(2) (1997) 52-62.

[6]. K.A. Harries, J.R. Ricles, S. Pessiki, R. Sause, Seismic retrofit of lap-splices in nonductile square columns using carbon fiber-reinforced jackets. ACI Struct. J. 103(6) (2006) 874-884.

[7]. G.E. Thermou, S.J. Pantazopoulou, Fiber reinforced polymer retrofitting of substandard RC prismatic members. Journal of Composites for Construction. ASCE 13(6) (2009) 535546.

[8]. T.C. Triantafillou, C.G. Papanicolaou, P. Zissimopoulos, T. Laourdekis, Concrete confinement with textile-reinforced mortar jackets. ACI Struct. J. 103(1) (2006) 28-37.

[9]. T.C. Triantafillou, C.G. Papanicolaou, Shear strengthening of reinforced concrete members with textile reinforced mortar (TRM) jackets. Mater Struct 39(285) (2006) 93103. 
[10]. D.A. Bournas, P.V. Lontou, C.G. Papanicolaou, T.C. Triantafillou, Textile-reinforced mortar versus fiber-reinforced polymer confinement in reinforced concrete specimens. ACI Struct J 104(6) (2007) 740-748.

[11]. A. D'Ambrisi, L.Feo, F. Focacci, Experimental analysis on bond between PBO-FRCM strengthening materials and concrete. J Compos B Eng 44(1) (2013) 524-532.

[12]. A. D'Ambrisi, L. Feo, F. Focacci, Bond-slip relations for PBO-FRCM materials externally bonded to concrete. J Compos B Eng 43(8) (2012) 2938-2949.

[13]. G.E. Thermou, S.J. Pantazopoulou, Metallic fabric jackets: an innovative method for seismic retrofitting of substandard RC prismatic members. fib Struct. Concr. J. 8(1) (2007) 35-46.

[14]. G.E. Thermou, K. Katakalos, G. Manos, Concrete confinement with steel-reinforced grout jackets. Mater. Struct. 48(5) (2015) 1355-1376.

[15]. G.E. Thermou, K. Katakalos, G. Manos, Influence of the cross section shape on the behaviour of SRG-confined prismatic concrete specimens. Mater. Struct. 49(3) (2016) 869-887.

[16]. G.E. Thermou, K. Katakalos, G. Manos, Influence of the loading rate on the axial compressive behavior of concrete specimens confined with SRG jackets. ECCOMAS Thematic Conference COMPDYN, Greece, Kos, Paper No. 1482, 2013.

[17]. G.E. Thermou, I. Hajirasouliha, Compressive behaviour of concrete columns confined with Steel-Reinforced Grout jackets. Comp. Part B: Eng. 138 (2018) 222-231.

[18]. G.E. Thermou, I. Hajirasouliha, Design-oriented models for concrete columns confined by steel-reinforced grout jackets. Construction and Building Materials, 178 (2018) 313326. 
[19]. G.E. Thermou, K. Katakalos, G. Manos, Experimental investigation of substandard RC columns confined with SRG jackets under compression. Composite Structures, 184 (2018) 55-65.

[20]. G.E. Thermou, G. de Felice, S. De Santis, S. Alotaibi, F. Roscini, I. Hajirasouliha, M. Guadagnini, Mechanical characterization of multi-ply steel reinforced grout composites for the strengthening of concrete structures. 9th International Conference on FibreReinforced Polymer (FRP) Composites in Civil Engineering (CICE 2018), Paris 17-19, (2018) Paper No. 30.

[21]. G.E. Thermou, I. Hajirasouliha, Assessment of compressive strength of steel-reinforced grout jacketed concrete columns. 9th International Conference on Fibre-Reinforced Polymer (FRP) Composites in Civil Engineering (CICE 2018), Paris 17-19, (2018), Paper No. 69

[22]. G.E. Thermou, I. Hajirasouliha, Evaluating the confining effects of steel-reinforced grout jacketing: An experimental study. ACIC 2017, Sheffield, UK, (2017) Paper No. 56.

[23]. G.E. Thermou, V.K. Papanikolaou, I. Hajirasouliha, A Novel method for seismic retrofitting of substandard RC columns using steel-reinforced grout jacketing. $16^{\text {th }}$ European Conference on Earthquake engineering, Thessaloniki, Greece, (2018) Paper No. 11063.

[24]. T.C. Triantafillou, C.G. Papanicolaou, Shear strengthening of reinforced concrete members with textile reinforced mortar (TRM) jackets. Materials and Structures (2006) 39:93-103

[25]. Y. Al-Salloum, M. Elsanadedy, S. Alsayed, R. Iqbal, Experimental and numerical study for the shear strengthening of reinforced concrete beams using textile reinforced mortar, J. Compos. Construct. 16(1) (2012) 74-90. 
[26]. R. Azam, K. Soudki, FRCM Strengthening of Shear-Critical RC Beams. Journal of Composites for Construction, 04014012, (2014).

[27]. D. Baggio, K. Soudki, M., Noel Strengthening of shear critical RC beams with various FRP systems. Constr Build Mater 66 (2014) 634-44.

[28]. Z.C. Tetta, L.N. Koutas, D.A. Bournas, Textile-reinforced mortar (TRM) versus fiberreinforced polymers (FRP) in shear strengthening of concrete beams. Composites Part B 77 (2015) 338-348.

[29]. S.M. Raoof, D.A. Bournas, TRM versus FRP in flexural strengthening of RC beams: Behaviour at high temperatures. Construction and Building Materials 154 (2017) 424437.

[30]. R. Azam, K. Soudki, J.S. West, M. Noël, Strengthening of shear-critical RC beams: Alternatives to externally bonded CFRP sheets. Construction and Building Materials 151 (2017) 494-503.

[31]. J.H. Gonzalez-Libreros, C. Sabau, L.H. Sneed, C. Pellegrino, G. Sas, State of research on shear strengthening of RC beams with FRCM composites. Construction and Building Materials 149 (2017) 444-458.

[32]. A. Younis, U. Ebead, K.C. Shrestha. Different FRCM systems for shear-strengthening of reinforced concrete Beams. Construction and Building Materials 153 (2017) 514-526.

[33]. T. Trapko, D.a Urbańska, M. Kamiński, Shear strengthening of reinforced concrete beams with PBO-FRCM composites. Composites Part B 80 (2015) 63-72.

[34]. C. Escrig, L. Gil, E. Bernat-Maso, F. Puigvert, Experimental and analytical study of reinforced concrete beams shear strengthened with different types of textile-reinforced mortar. Construction and Building Materials 83 (2015) 248-260.

[35]. Ombers L. (2015) Structural performances of reinforced concrete beams strengthened in shear with a cement based fiber composite material. Compos Struct 122 (2015) 316-329. 
[36]. G. Loreto, S. Babaeidarabad, L. Leardini, A. Nanni, RC beams shear-strengthened with fabric-reinforced cementitious- matrix (FRCM) composite. Int J Adv Struct Eng 7 (2015) $341-352$.

[37]. Z.R. Aljazaeri, J.J. Myers, Strengthening of Reinforced-Concrete Beams in Shear with a Fabric-Reinforced Cementitious Matrix. J. Compos. Constr. 21(5) (2017) 04017041.

[38]. J.H. Gonzalez-Libreros, L.H. Sneed, T. D’Antino, C. Pellegrino, Behavior of RC beams strengthened in shear with FRP and FRCM composites. Engineering Structures 150 (2017) 830-842.

[39]. A. Napoli, G. de Felice, S. De Santis, R. Realfonzo, Bond behaviour of Steel Reinforced Polymer strengthening systems. Composite Structures 152 (2016) 499-515.

[40]. S. De Santis, A. Napoli, G. de Felice, R. Realfonzo, Strengthening of structures with Steel Reinforced Polymers: A state-of-the-art review. Compos Part B-Eng 104 (2016): 87-110.

[41]. Dutton, W.A. Andy, N.A. Hoult, Curvature monitoring of beams using Digital Image Correlation. J. Bridge Eng., ASCE, 19(3) (2014) 05013001-13.

[42]. ASCE 41-06. Seismic rehabilitation of existing buildings. Edition: 1st. American Society of Civil Engineers; 2007

[43]. Eurocode 2. Design of concrete structures-Part 1-1: General rules and rules for buildings. prEN 1992-1-1:2003E, European Committee for Standardization (CEN), Brussels, 2003.

[44]. ACI 318-08. Building code requirements for reinforced concrete and commentary. American Concrete Institute, Farmington Hills, MI, 467.

[45]. American Concrete Institute (ACI) Committee, Guide for the design and construction of externally bonded FRP systems for strengthening concrete structures, ACI 440.2R-08, Farmington Hills, MI, 2008. 
[46]. ACI (American Concrete Institute), Guide to design and construction of externally bonded fabric-reinforced cementitious matrix systems for repair and strengthening concrete and masonry structures, ACI 549.4 R-13, ACI Committee 549, Farmington, MI, 2013.

[47]. fib Bulletin 14, Externally bonded FRP reinforcement for RC structures, Report by Task group 9.3, fédération internationale du béton (fib), Lausanne, Switzerland, 2001

[48]. A. Khalifa, W.J. Gold, A. Nanni, A.M.I. Aziz, Contribution of externally bonded FRP to shear capacity of RC flexural members. ASCE Journal of Composites for Construction, 2(4) (1998) 195-202.

[49]. T.C. Triantafillou Shear strengthening of reinforced concrete beams using epoxy-bonded FRP composites. ACI Structural Journal 95(2) (1998) 107-115.

[50]. S.J. Pantazopoulou, S.P. Tastani, G.E. Thermou, T. Triantafillou, G. Monti, D. Bournas, M. Guadagnini, Background to European seismic design provisions for the retrofit of R.C. elements using FRP materials. Structural Concrete, Journal of the fib, 17(2) (2016) 133305.

[51]. S. De Santis, G. de Felice, Steel reinforced grout systems for the strengthening of masonry Structures. Composite Structures 134 (2015) 533-548.

[52]. C.P. Antonopoulos, T.C. Triantafillou, Experimental investigation of FRP-strengthened RC beam-column joints. Journal of Composites for Construction 7(1) (2003) 39-49. 